\title{
El complejo urbano transfronterizo Melilla-Nador
}

\author{
The Melilla-Nador cross-border urban complex
}

\author{
Gabino Ponce Herrero ${ }^{1 *}$ (1) \\ Pablo Martí Ciriquián² (D)
}

\section{Resumen}

Los procesos de globalización están provocando una nueva reestructuración de la división internacional del trabajo, en el que las viejas fronteras, sometidas a intensos procesos de cambio, alteran su función de aislar, para convertirse, en ocasiones, en puentes de intercambio. Es un proceso selectivo, que endurece los flujos de mano de obra y mercancías y favorece el tránsito de capitales. La frontera de Melilla (España) y Nador (Marruecos), pese al llamativo drama humano del control migratorio, se convierte en oportunidades para el capital trasnacional, precisamente por el desequilibrio socioeconómico existente. A partir de análisis cartográficos de densidades, del mercado laboral y de la oferta y demanda de servicios, se comprueba la formación de una región funcional transfronteriza, cuya forma urbana tiende a la conurbación, jerarquizada por Melilla, sin que existan planes de integración, comunes en el proceso de reformulación de las fronteras dentro de la Unión Europea. Se concluye que la frontera asimétrica es el motor de la economía de una amplia región transfronteriza, desprovista de otros recursos, conforme con un enfoque geoeconómico que explota (y mantiene) la desigualdad, y que la forma urbana se asemeja al modelo de los complejos urbanos transfronterizos latinoamericanos. El reconocimiento de esta realidad es básico para el desarrollo de futuras estrategias de cohesión e integración supraestatales, y para la puesta en marcha de planes de gobernanza conjunta.

Palabras clave: frontera; urbanismo; asimetría; complejo urbano transnacional; Melilla-Nador.

\begin{abstract}
Globalisation is restructuring the international division of labour. Old borders are undergoing intense changes - their function of isolation is being altered and some are becoming bridges for trade. This process is selective. Flows of labour and goods are tightly controlled, while the movement of capital is favoured. Despite the striking human drama of migration control, the borders of Melilla (Spain) and Nador (Morocco) have created opportunity for transnational capital, precisely because of the socioeconomic imbalance along the border. After analysing density maps, the labour market, and the supply and demand for services, we observed that a cross-border functional region is being formed: its urban form tending towards a conurbation hierarchically organised around Melilla and lacking any planned integration. Such integration plans are common within the European Union in border reconfiguration processes. We conclude that the asymmetrical frontier is driving the economy of a broad cross-border region that is devoid of other resources, and is following a geoeconomic approach that exploits (and maintains) inequality. Furthermore, the urban shape is similar to the model of Latin American crossborder cities. It is essential to acknowledge this reality and develop strategies of supranational cohesion and integration, and implement joint governance plans.
\end{abstract}

Keywords: border; urbanism; asymmetry; transnational urban complex; Melilla-Nador.

\footnotetext{
1 Departamento de Geografía Humana, Universidad de Alicante, España. gabino.ponce@ua.es. * Autor para correspondencia.

2 Departamento de Edificación y Urbanismo, Universidad de Alicante, España. pablo.marti@ua.es
} 


\section{Introducción}

El Estrecho de Gibraltar es zona de alto valor estratégico, en el que los enclaves de Gibraltar, Ceuta y Melilla desempeñan la función de principales puertos de avituallamiento y tránsito de mercancías y pasajeros entre continentes (Europa, África y Asia por el Canal de Suez) y grandes zonas geopolíticas (Mediterráneo-Atlántico). Además, Ceuta y Melilla, ciudades españolas enclavadas en la costa mediterránea de Marruecos, cumplen la función de cabeza de puente por sus ventajas comparativas —excelentes puertos naturales al final de las rutas terrestres naturales de comunicación-y competitivas - potentes infraestructuras europeas- frente a las propias de ese país africano. La destacada función comercial de esas dos ciudades españolas, ubicadas en las dos terminales del sistema viario terrestre de Marruecos, las ha convertido en polos de desarrollo de las zonas agrícolas de sus alrededores, hasta configurar, en el caso de Melilla aquí analizado, un área urbana con marcadas características metropolitanas, bien que afectada por la frontera y la muy pequeña superficie del municipio español.

Este artificial límite administrativo ha evolucionado desde una potente demarcación geopolítica, heredada del régimen colonial, hacia un sistema de relaciones convergentes entre los agentes locales de uno y otro lado, condicionada por la geoestrategia de ambos países. La tensa y dinámica relación entre convergencia y divergencia en las ciudades de frontera ha sido identificada como oportunidad para el desarrollo de un sistema económico propio, con la condición de que exista un notable diferencial de rentas (Glassner y De Blij, 1980). Según el Banco Mundial, el Producto Interior Bruto (PIB) de España multiplica por 9 el de Marruecos (28.208,9 y 3.022,9 \$ respectivamente en 2017), cuando el de Estados Unidos multiplica por 6 el de México, espacio en el que se dan casos similares (Alegría, 1992, 2000 y 2008). Se concreta, de ese modo, una fuerte asimetría que potencia el intercambio de mercancías, personas, servicios y capital, aprovechada por el neoliberalismo trasnacional, que actúa selectivamente en las fronteras: por un lado, las debilita para el flujo de capitales y mercancías mientras, por otro lado, las endurece para el tránsito de personas y su corolario de ideas, religiones, señas de identidad y como controles sanitarios (Anderson, 2001). Tal fenómeno, característico del borde en Melilla, ha sido caracterizado conceptualmente como teichopolítica, al referirse al énfasis contemporáneo por levantar muros en el Río Grande, que contienen la migración, pero son permeables al capital (Rosière, 2011).

En estos casos, la frontera, con todos sus inconvenientes, evoluciona hacia un ámbito de oportunidad para un intercambio selectivo, que provoca una acumulación humana, manifiesta en diferentes formas de desarrollos urbanos en uno y otro lado. A partir del estudio de las relaciones entre las ciudades de San Diego (EE.UU.) y Tijuana (México) separadas también por una valla, Herzog (1990) acuñó el concepto de "metrópolis transfronteriza". Que ha sido criticado por cuanto, de hecho, las desigualdades en normas y regulaciones y las tensiones, impiden que el conglomerado urbano funcione como una auténtica región metropolitana (Dilla, 2008, 2015; Dilla y Breton, 2018). Así, del avance de los estudios sobre el urbanismo de frontera, nuevas aportaciones han introducido en el debate los modelos de "ciudades transfronterizas" (Valero, 2008) bajo el supuesto de que ambas partes tienden hacia una integración; el de "conurbaciones transfronterizas" (Peña, 2008) reseñando las dificultades de planificar ambos lados de la ciudad y, por consiguiente, las diferentes realidades urbanas generadas, y el de "complejos urbanos transfronterizos" (Dilla, 2015) que incorpora toda la complejidad económica, política, social, étnica y cultural de las ciudades duales en las fronteras latinoamericanas y se aleja del modelo de ciudad estándar. Este autor señala la pervivencia en el tiempo de esa asimetría como motor urbano —que parece mantenerse en Melilla-, y la contrapone a los modelos de integración entre ciudades fronterizas dado en la Unión Europea (UE), donde se ha desarrollado el concepto de "ciudad binacional", auspiciado por una potente estrategia de cohesión social, sobre una población que comparte una misma cultura y escenario geopolítico y, a partir de la supresión de las fronteras internas, han desarrollado un fuerte sentimiento de pertenencia a una misma comunidad (Ehlers, Buursink, Velde y Houtum, 2000).

Pese a que una parte se beneficie de las políticas de cohesión europeas, no parece que éste sea el caso de la región transfronteriza de Melilla, más semejante a los casos latinoamericanos expuestos. Sin embargo, una experiencia asiática podría aportar otro referente. Se trata del "Triángulo de Desarrollo Indonesia-Malasia-Singapur" (plan SIJORI de 1994), que pone al servicio de la ciudad de Singapur, los recursos humanos y naturales de los territorios vecinos de Malasia e Indonesia, como estrategia regional para captar inversiones transnacionales. Descrito por Jessop (2004) para establecer el concepto aquí utilizado de "región transfronteriza" (más genérico que los anteriores, referidos a la forma urbana), la economía de Singapur se beneficia de la mano de obra barata y de los recursos que, a diario, cruzan las fronteras 
internacionales, en dinámica que recuerda, con todas las salvedades, al flujo cotidiano de "trabajadores autorizados" entre una y otra parte de la región transfronteriza de Melilla, como resultado de la "Declaración de Barcelona" de 1995, en la que se proponía la colaboración económica y financiera para el desarrollo de una "zona de prosperidad compartida".

Analizados con profusión los problemas humanitarios y geopolíticos de la ciudad de Melilla (Aziza, 2006; Ferrer, 2008; González y Pérez, 2008; Iglesias, 2011; Goye, 2011; Martín, 2015; Barras y García, 2015; Ferrer y Gabrielli, 2018, entre otras referencias actuales), el propósito de este trabajo se centra en el intento de definir el espacio vinculado funcionalmente, la forma urbana en que se estructura, los agentes causales, las tendencias y las deficiencias de los escasos y fragmentarios planes de ordenación territorial. Objetivo esencial es comprobar si la forma urbana se ajusta a alguno de los modelos interpretativos expuestos, para contribuir a esas teorías con un estudio de caso.

Los objetivos propuestos son identificar el funcionamiento de esa economía transfronteriza en los aspectos que atañen a las funciones y forma urbana, a partir de los flujos económicos y sociales. Definir el alcance de esa aglomeración urbana funcional. Valorar su jerarquización e intentar definir el modelo teórico que más se ajusta al caso estudiado, como paso primero y esencial para el desarrollo posterior de estrategias integradas de gobernanza.

\section{Metodología}

El área de estudio de la región transfronteriza se concreta en la ciudad autónoma de Melilla (España) y en la provincia de Nador (Marruecos). Melilla, con un apretado término municipal $-12,3 \mathrm{~km}^{2}-$ contaba en 2018 con 86.384 habitantes, y un crecimiento del 45\% desde 1996, cuando el crecimiento medio de España en ese periodo ha sido del 18\%. La provincia de Nador contaba en 2014 (último censo de Marruecos) con 565.426 habitantes, lo que supone una aglomeración humana de más de 650.000 habitantes dentro de un radio de unos $50 \mathrm{~km}$. El antiguo puerto de Melilla, dividido por la frontera, constituye la vía de intercambio comercial más importante de la mitad oriental de Marruecos, con un tráfico conjunto de 4,6 millones de toneladas en 2018. A lo largo de la Carretera Nacional 19, que parte de ese puerto, se ha desarrollado un gran corredor transfronterizo, por el que, a diario, pasan unas 20.000 personas y unos 5.000 vehículos. Ese eje viario vertebra la provincia de Nador, cuyos habitantes, por concierto específico del Acuerdo Schengen, desde 1995 están exentos de visado para el tránsito y el "pequeño tráfico fronterizo" (Boletín Oficial de la Ciudad Autónoma de Melilla [BOME], 2019). La frontera deviene en oportunidad para una provincia de base agrícola ( $26 \%$ de la población activa en 2016), donde el 50\% de la población activa se ocupa en el sector terciario (servicios banales y comercio).

Figura 1. Mapa de localización

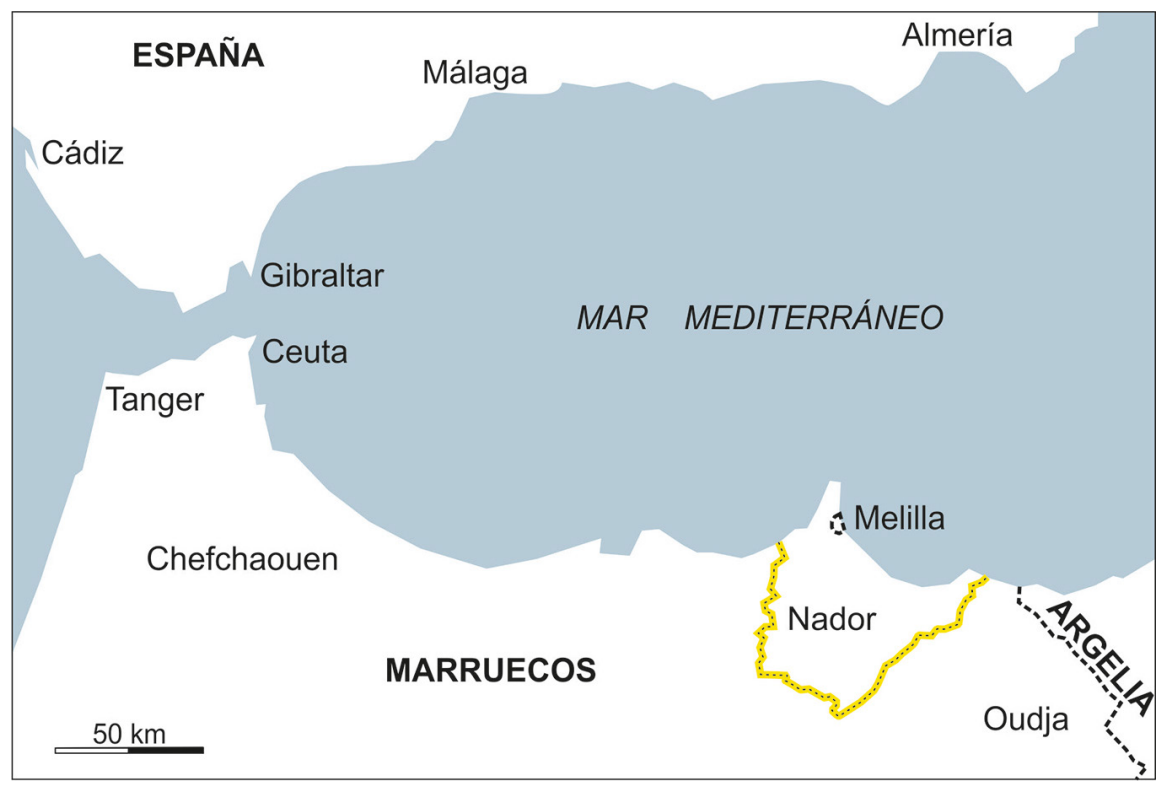

Fuente: Google Maps, 2019. Elaboración propia 
Los intensos flujos de movilidad humana, de mercancías y de capitales determinan los comportamientos de sus habitantes y son fundamentales en la organización — jerarquizada - de los espacios urbanos sobre un radio que supera los $50 \mathrm{~km}$ más allá de la frontera. El sistema político estatal —más en España que en Marruecos-intenta aplicar criterios urbanísticos para ordenar el territorio. Sin embargo, son las prácticas sociales derivadas de las intensas relaciones transfronterizas - formales e informales- las que adquieren mayor protagonismo en los procesos de creación de ciudad, en sus diversas fórmulas. Con ese enfoque, se aborda la cuestión de la dimensión territorial del área vinculada (aspecto hasta ahora no analizado), y su paulatina organización dependiente, que deriva necesariamente en las reflexiones planteadas sobre la gobernanza del espacio social bipolar que gravita en torno a la frontera hispano-marroquí.

En ese contexto, las relaciones sociales tejen redes de interdependencia plasmadas en redes urbanas que gravitan sobre la frontera, que actúa como filtro selectivo de los procesos de intercambio desigual. Se sustenta la hipótesis de que la ciudad española de Melilla, que extiende su influencia urbana sobre buena parte la provincia marroquí de Nador, cumpliría el papel de "capital funcional europea" en un contexto transfronterizo y transcontinental muy asimétrico, propio no de la cohesión de las regiones fronterizas intraeuropeas, sino de los complejos urbanos transfronterizos que propone Dilla (2008) para las formas urbanas a uno y otro lado de fronteras muy desiguales, y que Sohn (2014) define como un "modelo geoeconómico" de explotación económica de las fronteras.

Para ello se manejarán fuentes estadísticas de España y Marruecos (menos desarrolladas y explicitas: se ha procurado utilizar siempre el último año de referencia en Marruecos - 2016- para las comparaciones, lo que retrotrae en algunos años los análisis). Ante las insuficiencias de las herramientas que ofrecen los proyectos de identificación de áreas urbanas europeas, se han empleado métodos directos para la delimitación y organización del conglomerado urbano, tales como la densidad (de intersecciones viarias, de habitantes y de lugares de trabajo) y la contigüidad de usos urbanos (Feria, 2010 y 2013; Salom y Albertos, 2014; Duarte y Troncoso, 2012). Complementado por el trabajo de campo que, durante años, realizaron los autores de este trabajo para elaborar el plan general de Melilla. La metodología se inspira en los trabajos elaborados para el análisis de las formas urbanas surgidas en torno a las fronteras asimétricas de América Latina (Dilla, 2008; Herzog y Sohn, 2014; Wong-González, Oddone y Barajas, 2017).

\section{Resultados}

\subsection{La configuración histórica de la región transfronteriza}

El promontorio que sustenta la ciudad vieja de Melilla presenta una estratégica ubicación en el Mar Mediterráneo. Pequeña península de fácil defensa, ha sido clave para que todas las culturas que han gobernado el Mediterráneo hayan instalado alguna colonia, con una ocupación prácticamente ininterrumpida como ciudad habitada en época púnica, romana y musulmana. El núcleo genético - Melilla la Vieja- es un peñón rodeado de mar que, además, protege una pequeña bahía donde se instaló un puerto seguro, cerca de un abastecimiento constante de agua —el Río de Oro-, que convertía a la ciudad en fondeadero idóneo para reparar los barcos y aprovisionar a las tripulaciones.

La vieja medina —-Barrio de Medina Sidonia (Melilla la Vieja) — aparece por la voluntad expresa de crear un asentamiento militar — plaza fuerte-, situada en un punto estratégico del comercio marítimo en el Estrecho de Gibraltar. Convertida en ciudad española en 1497, la ciudad sumó a ese bagaje histórico una excelente trama de murallas y fortificaciones, levantadas con estilos propios del Renacimiento y del Barroco. La sucesión de trabajos militares para la defensa de la ciudad se plasma en la existencia de hasta cuatro diferentes recintos fortificados y diferentes fuertes externos. Con el Tratado de Wad-Ras entre España y el Sultán de Marruecos, en 1860 se estableció la frontera a partir del alcance de un cañón, definiendo un semicírculo que envuelve $12,3 \mathrm{~km}^{2}$ en torno al promontorio original.

En 1906, en la Conferencia de Algeciras, por cuestiones de balance geoestratégico, las tres grandes potencias coloniales en África - Francia, Inglaterra y Alemania - permitirían a España la conquista paulatina del Norte de Marruecos a partir de las plazas fuertes de Melilla y Ceuta. El Tratado de Fez - 1912_ entre España y Francia, definiría la franja de servidumbre española en Marruecos, ocupada militarmente bajo el régimen de "protectorado" hasta 1956. La ciudad de Melilla seguiría como plaza militar, junto a la vecina ciudad de Nador, capital de la nueva región administrativa española. Con la independencia de Marruecos, Melilla fue adscrita a la provincia de Málaga (en la Península Ibérica) hasta que en 1995 
alcanzó el rango de "ciudad autónoma", similar al de "comunidad autónoma" con que se organiza administrativamente España desde 1981.

Figura 2. Plano de la ciudad y término de Melilla en 1909

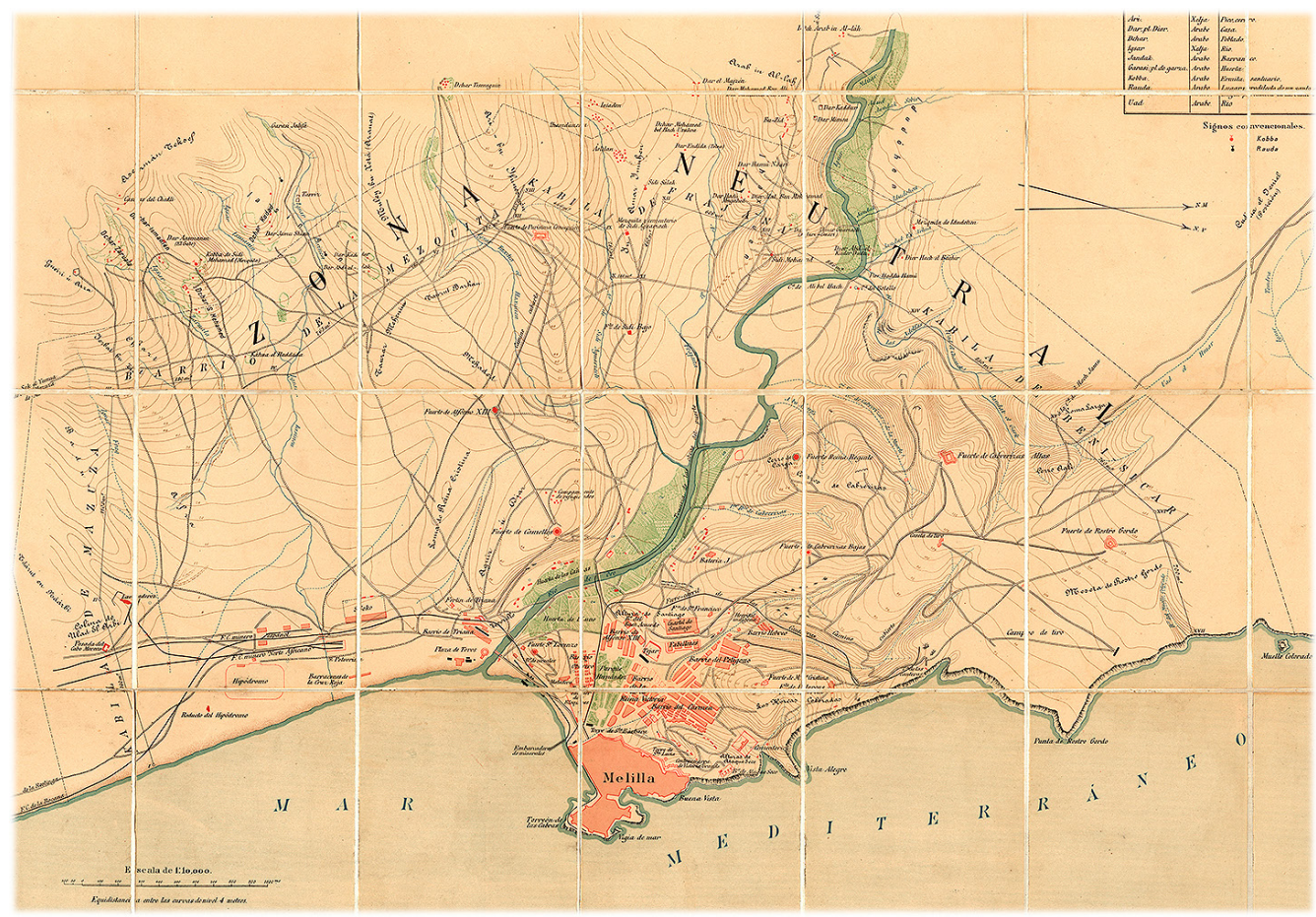

Fuente: Depósito de la Guerra. Plano de campo exterior de Melilla y croquis del campo fronterizo. Levantado en 1894 ampliado y puesto al día en 1909. Cartoteca Digital del Institut Cartogràfic i Geològic de Catalunya

Figura 3. Melilla en el contexto subregional de Marruecos (provincia de Nador). Densidades de población en 2015

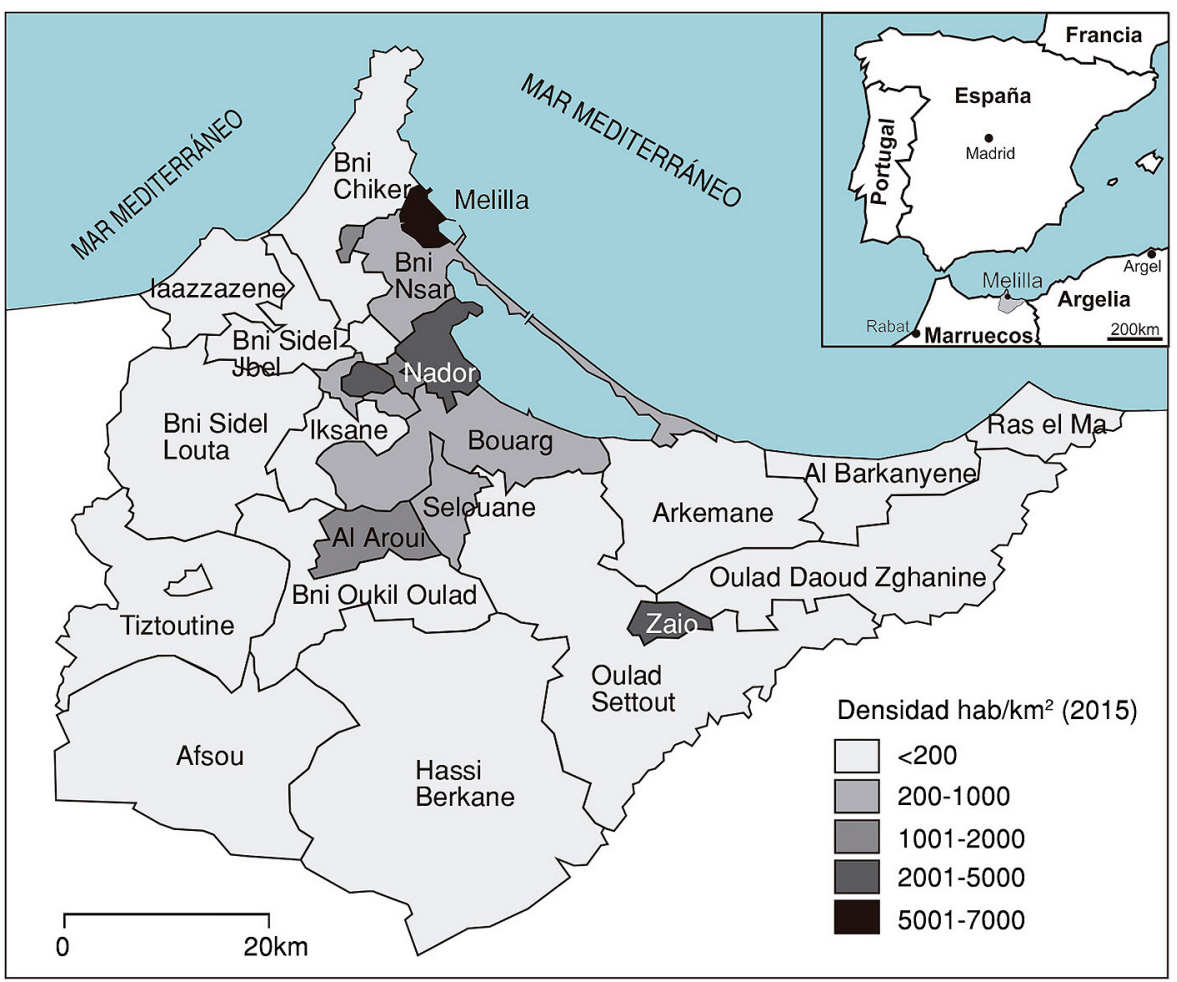

Fuente: INE y Haut-Commissariat au Plan du Maroc-Centre National de Documentation (2016). Elaboración propia 
Es ciudad reivindicada por Marruecos desde los años 1970, por consideraciones geográficas, pero defendida por España por cuestiones históricas (ciudad española antes de la formación del sultanato de Marruecos). Se mantiene candente la cuestión, pero se aplaza por cuanto la condición de puerto franco de Melilla mantiene la economía de la actual provincia marroquí de Nador. Al tiempo, desde España, se favorece ese espacio de intercambio internacional, como fundamento económico de una ciudad carente de otro tipo de recursos. De ese modo, a propuesta de España, Melilla no forma parte del territorio aduanero de la Unión Europea - UE-, está exenta de la mayor parte de los impuestos especiales, y cuenta con un trato preferencial para sus exportaciones a la UE, según el Acta de Adhesión (Comisión Europea, 1985) y el Reglamento CE 1140/2004 (Comisión Europea, 2004).

Figura 4. Esquema de las principales infraestructuras de Marruecos (los grafos son proporcionales a la intensidad del uso y número de habitantes: relación aritmética). Se observa el importante flujo de la CN 19 Melilla-Nador

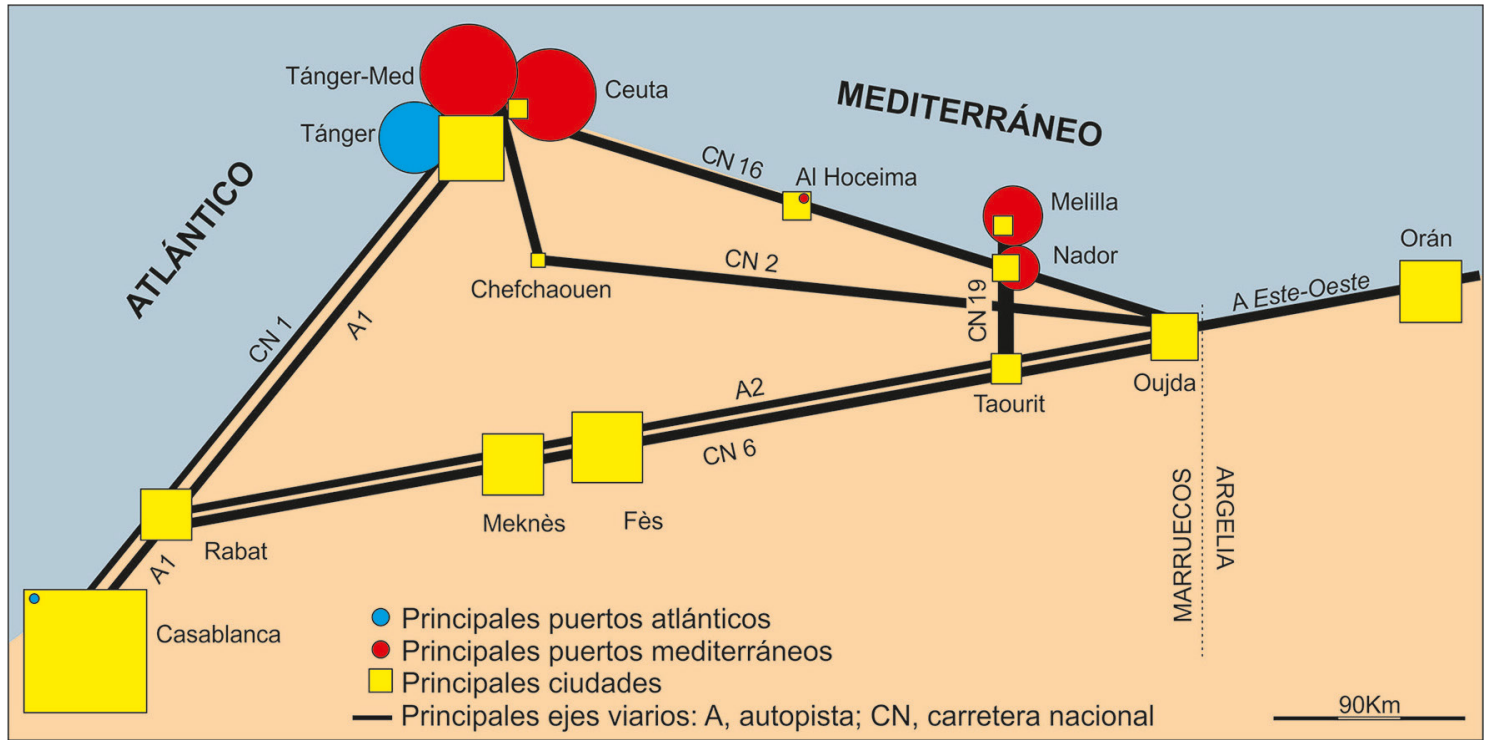

Fuente: Ministère de l'Equipement, du Transport, de la Logistique et de l'Eau (METLE) y Haut-Commissariat au Plan du Maroc-Centre National de Documentation (2016) y Ministerio de Fomento, Autoridad Portuaria e Instituto Nacional de Estadística (INE) (2016). Elaboración propia

De hecho, Melilla y Ceuta han funcionado históricamente como cabeza de puente — de gestión española- en el tráfico de personas y mercancías entre Europa y África. Con estratégica ubicación, en ambas ciudades españolas converge la red viaria marroquí en su salida hacia el Mediterráneo y Europa. Así, sus puertos - francos administrativa y fiscalmente — han capitalizado los flujos Marruecos (África)-España (Europa). La apertura en 2007 del puerto Tánger Med —alejado $44 \mathrm{~km}$ de esa ciudad y ubicado en el Mediterráneo, a $15 \mathrm{~km}$ de Ceuta - tenía la misión de captar para Marruecos una parte del negocio marítimo generado en el Estrecho de Gibraltar, bajo las mismas características de puerto y zona franca, en competencia con Ceuta y el enclave británico de Gibraltar. Entre tanto, Melilla sigue ejerciendo de principal puerto de la mitad oriental de Marruecos — menos desarrollada económicamente-.

Tabla 1. Principales puertos de Marruecos, Ceuta y Melilla, año 2015

\begin{tabular}{|l|r|r|}
\hline \multicolumn{1}{|c|}{ puerto } & Pasajeros (miles) & Tn mercancias (miles) \\
\hline Tánger Med & 2.399 & 40.671 \\
\hline Tánger Ville & 1.280 & \\
\hline Ceuta & 1.923 & 1.935 \\
\hline Melilla & 889 & 1.142 \\
\hline Nador & 424 & 2,9 \\
\hline Al Hoceima & 42 & \\
\hline Casablanca & 28 & 31,8 \\
\hline
\end{tabular}

Fuente: METLE (2016) y Ministerio de Fomento, Autoridad Portuaria (2016). Elaboración propia 
Figura 5. Intensidad de tráfico medio diario en la provincia de Nador y Melilla

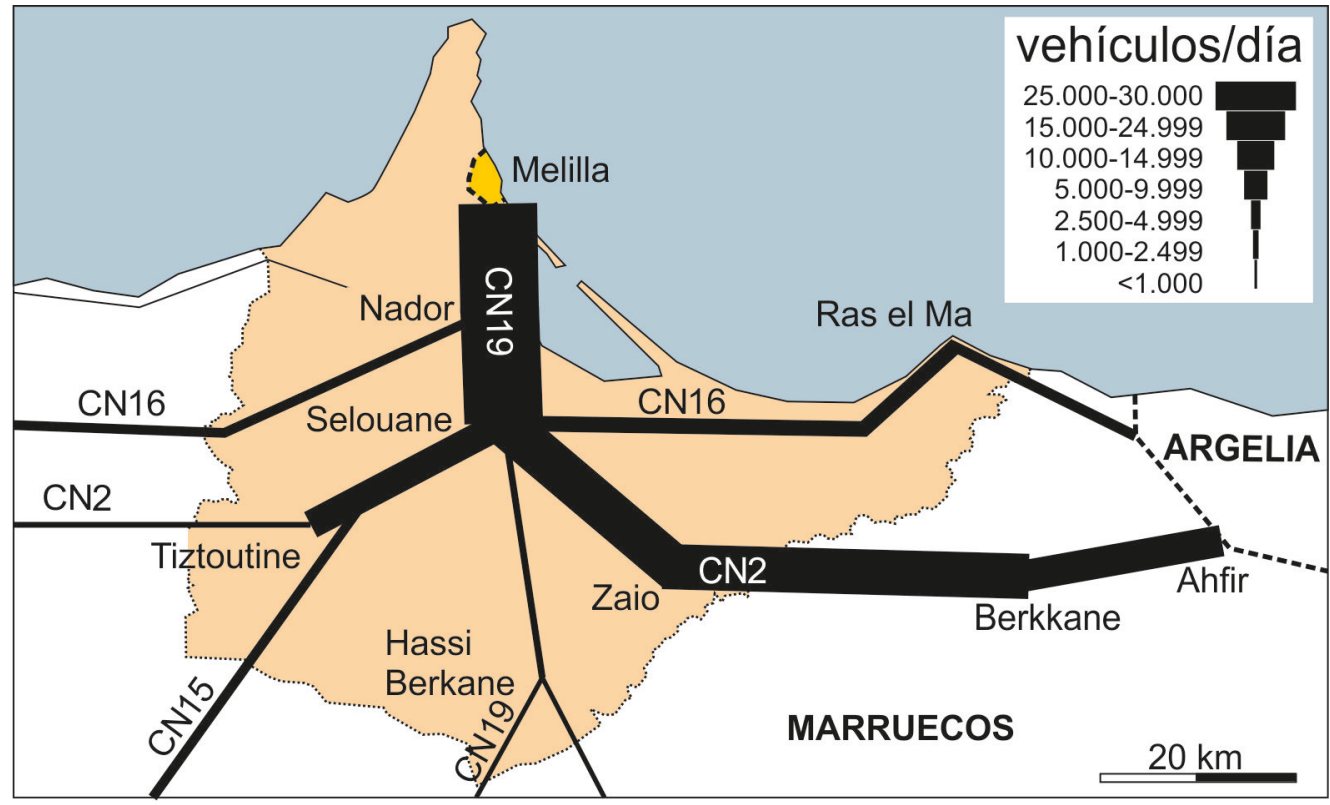

Fuente: Recueil du trafic routier, 2016. METLE. Elaboración propia

Los flujos de mercancías y pasajeros muestran que la región transfronteriza, que se organizó funcionalmente durante el "Protectorado" (1912-1956) en torno al puerto y a la ciudad de Melilla, tras la independencia sigue vinculada a las funciones de ese puerto (ahora partido en dos por la frontera). La Carretera Nacional 19, con uno de los indicadores de tráfico más elevados del país, constituye la arteria que organiza el principal corredor funcional (norte-sur) de la mitad oriental del país. Conecta en Taourit (Figura 4) con el gran eje oeste-este que, desde Casablanca, por la Autovía A2 y la CN 6, atraviesa todo el centro de Marruecos y conecta, en Oujda, con la Autovía Este-Oeste que discurre por todo el norte de Argelia hasta Túnez. En ese contexto, la CN 19 hacia Melilla constituye la puerta de entrada y salida de la mitad oriental de Marruecos. En 2016, el tráfico medio diario de vehículos en la CN19 fue de 23.609, uno de los más importantes del país, sólo rebasado por los de las aglomeraciones urbanas de Casablanca y Tetuán. El sistema se complementa con dos ejes transversales este-oeste. Uno es la CN16 (Carretera del Mediterráneo o del Rif), que discurre junto a la costa, comunicando Tánger con la frontera de Argelia, y da salida a la zona rural del Rif, con un tráfico medio diario de 8.545 vehículos. El otro es la CN 2, que discurre por la vertiente meridional del Rif, en paralelo al anterior, con un tráfico medio diario de 9.934 vehículos. Ambos son ejes de mucha menor entidad, con un marcado carácter subregional, en un entorno de base agrícola.

El Índice Dinámico de Densidad de Tráfico, equiparable a la intensidad del tráfico medio diario de vehículos, dentro de la provincia de Nador cartografía con gran precisión la articulación del corredor transfronterizo, ceñido a la provincia por el lado occidental, pero con desarrollo hasta la frontera con Argelia por el sector oriental. La alineación Melilla-Nador-Selouane constituye el eje central, con un flujo de vehículos diarios entre los 25.000 y los 30.000. A partir de Selouane, unos 20.000 vehículos diarios se encaminan hacia la frontera con Argelia: 5.000 por Ras el Ma y 15.000 por Zaio-Berkkane-Ahfir. Mientras los tráficos por los demás vectores del sistema son mínimos más allá de los límites de la provincia.

Existen diferentes índices para medir la jerarquía y accesibilidad en una red viaria. En este caso, por su valor como indicador en un sistema de información geográfica y por la disponibilidad de datos, se ha empleado el Índice de Potencial Económico (López Suárez, 2007), en el que se contemplan los centros de actividad económica, ponderados por su importancia (en este caso por su número de habitantes) y por el tiempo empleado en acceder a ellos por el sistema viario en automóvil estándar (que es el medio ordinario en la provincia de Nador). De poder disponer de otros datos estadísticos cualitativos de actividad para Marruecos, probablemente se hubiese disparado la importancia de Melilla que, no obstante, pese a su posición marginal en el sistema, ocupa en segundo lugar, detrás de Nador, con mayor número de habitantes y posición más centrada. 
Figura 6. Índice de Potencial Económico conforme a la accesibilidad

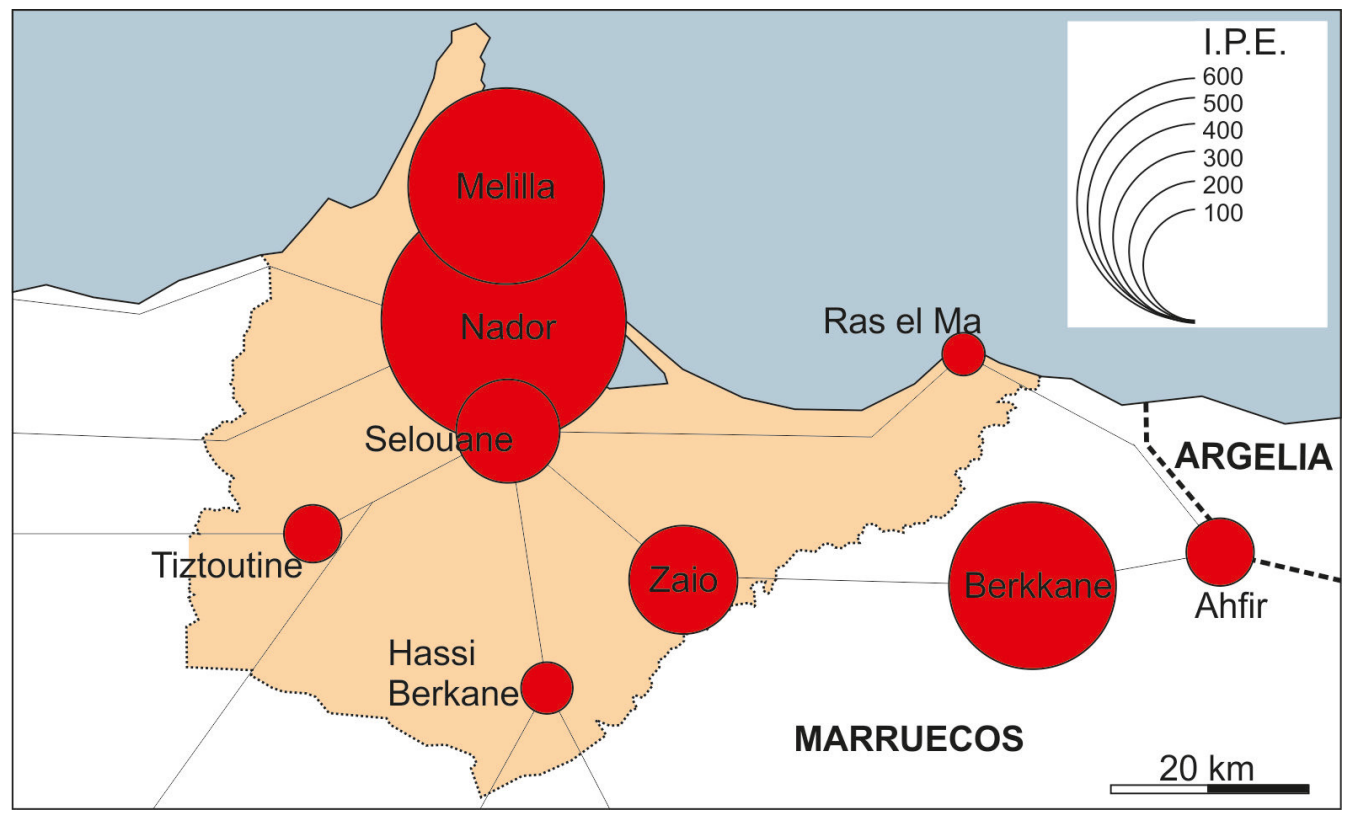

Fuente: Recueil du trafic routier, 2016. METLE, e INE. Elaboración propia

Se trata, en esencia, de un sistema viario concretado en el tránsito transfronterizo, que perfila un claro eje Melilla-Ahfir, o lo que es lo mismo España-Marruecos-Argelia. La frontera entre estos dos países permaneció cerrada hasta 2004 por motivos de disputa territorial, lo que alentó el contrabando y, desde su apertura, también un importante comercio transfronterizo, a donde llegan las mercancías compradas en Melilla (Daoudi, 2015). En esa región transfronteriza destaca la potencia del eje Melilla-Nador, con extensión hacia Selouane, donde se produce la primera ruptura significativa.

\subsection{La frontera como sistema económico}

Melilla es un puerto franco desde 1863. En 1955, la Ley de bases de régimen económico y financiero de Ceuta y Melilla (BOE 359, de 25/12/1955) ampliaba esa condición a todo el territorio de la ciudad, favorecido por una reducción fiscal del $50 \%$. Se potenciaba de ese modo una "economía de bazar" que seguía atendiendo a las ciudades marroquíes vecinas, al nutrido destacamento militar acantonado en la ciudad, a los visitantes del resto de España y al pasaje de los numerosos buques atraídos por los más competitivos precios de los carburantes.

La incorporación de España a la Comunidad Económica Europea (CEE) el 1 de enero de 1986 y un mayor control de sus fronteras exteriores, comenzaron a dificultar las ventas a los ciudadanos marroquíes. Especialmente a partir de la Ley de Represión del Contrabando (BOE 257, de 13/12/1995). Por otro lado, las nuevas estrategias defensivas de la UE y sus acuerdos con Marruecos hicieron innecesarias buena parte de las fuerzas militares acuarteladas en la ciudad, trasladadas a otras partes de España. Por último, el papel de "puerto gasolinera" fue decayendo al liberalizarse los combustibles, en favor de Gibraltar (Procesa, 2011).

Como medida paliativa a la crisis desencadenada por la alteración del contexto geoestratégico, en la incorporación de España a la CEE se decidió que Melilla quedara fuera del territorio aduanero de la UE. También quedaba exenta de los impuestos europeos (entre ellos del valor añadido [IVA]). De ese modo, el comercio con el resto de España y con el conjunto de la UE es considerado como importación y exportación, pero no está sujeto a aranceles, gracias al trato preferencial que la UE depara a la ciudad, conforme con el Acta de Adhesión (L-302, de 15/11/1985) y al Reglamento CE 1140/2004. Pero una zona franca funciona si tiene clientes, y la inclusión de Melilla dentro del espacio Schengen en 1995 supuso otra importante limitación a su área de influencia comercial sobre las provincias vecinas de Marruecos, que se ha solventado mediante otra excepcionalidad a la legalidad fronteriza europea.

En efecto, las diferencias de renta entre uno y otro país hacen de esta frontera una de las más desequilibradas del Mundo, como muestran algunos indicadores: en 2017, el PIB per cápita (en dólares 
USA) era de 28.209 para España y de 3.023 para Marruecos (Banco Mundial, 2018); en ese año, el Índice de Desarrollo Humano colocaba a España en el puesto 26 y a Marruecos en el 126 del Mundo; el gasto publico per cápita (euros) en salud era de 1.464 y de 50 y en educación de 1.027 y 153 respectivamente (United Nations Development Programme, 2015). En general, la oferta comercial es mucho mayor en calidad, cantidad, diversidad y buenos precios en Melilla (puerto franco) que en la provincia marroquí de Nador (Planet, 2002), afectada por un PIB per cápita — $1.913 €$ en 2016 - muy por debajo de la media de Marruecos - $2.705 €$ en ese año-.

Esas diferencias provocan un claro efecto atracción de la población marroquí y de otras procedencias que, de manera legal e ilegal, intentan cruzar la frontera: ejemplo son los 3.566 ilegales detenidos en 2014 (Migreurop, 2016), que suponen alrededor del 2\% del total de los llegados a Europa en ese año. Para controlar su acceso, entre 1998 y 2014 se han construido cuatro vallas que, en paralelo, circundan el reducido territorio de Melilla e imponen otra serie de condicionantes urbanísticos y logísticos a la ciudad, y al funcionamiento de su área de influencia natural, que depende en gran medida de las dinámicas comerciales y de servicios radicadas en Melilla.

Tales circunstancias, junto a las peculiaridades ya señaladas de plaza militar, puerto franco, escasez de recursos propios y de mano de obra, han generado un modelo específico de movilidad fronteriza diferenciada (López, 2012a), con las características que siguen. Las necesidades de mano de obra para el mercado laboral de Melilla se satisfacen mediante varias fórmulas. Por un lado, a petición de España a la UE, se conceden visados a los ciudadanos de la provincia marroquí de Nador, para que puedan acceder a diario a Melilla, sin necesidad de pasaporte (que sí hace falta para acceder al resto de España). Se permite así el acceso diario de una legión de marroquíes, estimada en unos 20.000 efectivos (López, 2012b), aunque el Plan de Movilidad de la ciudad, de 2015, estimaba un flujo medio de 21.000 viandantes y de 3.800 vehículos. De estimarse una ocupación máxima de 4 personas por vehículo, entrarían otras 15.200 personas por ese medio. Es dato que concuerda con las 40.000 personas que estimaba la Central General de Trabajadores de Melilla en 2014 (Euro press, 2014). Ese colectivo se emplea en el servicio doméstico (mujeres), en la construcción y en el comercio local y transfronterizo (porteadores). Trabajo en gran parte informal, que les impide acceder a los derechos laborales del sistema legal español (Kardal, 2012).

Es particular fenómeno de commuting, restringido a los habitantes de la provincia marroquí de Nador, extendido por un área de unos $40 \mathrm{~km}$ desde Melilla, origen de una potente corriente migratoria interna, desde otras provincias marroquíes hacia la ciudad de Nador, con el propósito de obtener ese visado. Es flujo de inmigrantes que genera una fuerte presión sobre el mercado de trabajo en Nador, desborda la oferta de empleo (frente a la demanda), presiona a la baja los salarios, favorece la economía informal y el contrabando, y provoca grandes desequilibrios en el sistema de urbanización, generando importantes aglomeraciones de infraviviendas en los municipios vecinos a Melilla (Kardal, 2012).

Tabla 2. Evolución población 2004-2014

\begin{tabular}{|l|r|r|r|r|}
\hline \multicolumn{1}{|c|}{ ámbito } & \multicolumn{1}{c|}{2004} & \multicolumn{1}{c|}{2014} & \multicolumn{1}{c|}{ tasa variación $\%$} & \multicolumn{1}{c|}{ t.c.i. \% } \\
\hline Melilla & 68016 & 84509 & 24,2 & 2,19 \\
\hline ciudad Nador & 124915 & 159590 & 27,8 & 2,48 \\
\hline provincia Nador & 726520 & 561070 & $-22,8$ & $-2,55$ \\
\hline Marruecos & 29680069 & 33848242 & 14,0 & 1,32 \\
\hline España & 43197684 & 46771341 & 8,3 & 0,80 \\
\hline
\end{tabular}

Fuente: Rouyame du Maroc. Recensement Générale, 2014. INE. Elaboración propia

La Tabla 2 recoge la evolución de la población entre 2004 y 2014 (último periodo intercensal de Marruecos), poniendo de manifiesto el destacado crecimiento de Melilla y Nador, por encima de las medias de Marruecos y España, que contrasta con la pérdida de habitantes de la provincia de Nador, por efectos de la emigración hacia la ciudad de Nador y hacia el exterior.

Por otro lado, los empleadores o empresarios de Melilla pueden solicitar a las autoridades españolas permisos concretos de residencia temporal y trabajo por cuenta ajena, para la contratación de trabajadores marroquíes, por lo general procedentes de la provincia de Nador. Al alcanzar un contrato legal pueden acceder a los derechos del sistema español de seguridad social: en 2016 eran 4.324 los trabajadores extranjeros que habían alcanzado esa situación legal (Delegación del Gobierno en Melilla, 2016). 
Además, en beneficio del comercio transfronterizo, se conceden "pases de favor" que permiten la entrada en Melilla de cualquier ciudadano marroquí por un periodo de 24 horas, con el propósito de realizar compras, que luego son revendidas en Marruecos. Sin embargo, el Sindicato Central General de Trabajadores de Melilla denunciaba, en 2014, que sólo el 10\% de las personas que circulan diariamente (en uno y otro sentido) por el paso fronterizo de Melilla, lo hace con visado. Es decir, son muchas más las que lo atraviesan sin ningún tipo de control, situación extensiva a las mercancías transportadas a pie por esas personas: hasta 70 kilos en grandes sacos, por lo común artículos de consumo ordinario, pero muy diverso (desde calzado hasta productos farmacéuticos, pasando por neumáticos, ropa y pequeños electrodomésticos).

Es actividad difícil de cuantificar, aunque existen diferentes estimaciones. En 2012, la Cámara de Comercio Americana en Marruecos consideraba que el comercio ilegal ocupaba a unas 45.000 personas de manera directa y a otras 400.000 de forma indirecta en las ciudades de Melilla y Ceuta, generando un negocio de 1.400 millones de euros al año, que suponía la tercera parte del PIB de Melilla (http://www. amcham.ma). Ese mismo año, la Cámara de Comercio de Oudja (capital de la región Oriental en que se integra la provincia de Nador) cifraba en unos 600 millones de euros/año el valor del comercio informal alrededor de la frontera de Melilla (Direction Regionale d'Oudja, 2012). En 2007, una encuesta marroquí sobre el sector informal ${ }^{3}$ señalaba que en la región Oriental, alrededor de 110.590 trabajadores se empleaban en esa actividad, de ellos, el 69,3\% en el comercio.

\subsection{Los servicios como motor de la región transfronteriza}

En el caso de Melilla, los indicadores analizados ponen de manifiesto una serie de debilidades estructurales en la economía de la ciudad. El producto interior bruto per cápita en 2018 (18.482 €) se halla por debajo de la media estatal ( $25.854 €$ ), esto es, supone el $71 \%$ de la ratio de España. Es cuestión histórica que ha ido empeorando desde el año 2000, cuando ese indicador suponía el $89 \%$ de la media estatal (Contabilidad Regional de España, INE, 2018). Con todo, se halla muy por encima del PIB per cápita de las provincias de Nador y Berkane, cifrado en 2016 en $1.913 €$, cuando la media del país era de $2.705 €$ (Direction de la Comptabilité Nationale, 2017). Se da, en ambos casos, una situación de debilidad económica (aunque con un balance muy favorable a Melilla), que favorece contemplar la frontera como recurso.

La escasez de recursos de Melilla, con un término municipal tan reducido y aislado, determina una muy limitada oferta laboral, de forma que, en 2019, la tasa de desempleo media era del 26\%, cuando la del Estado era del 15\% (Encuesta de Población Activa, INE, 2019). Por el contrario, la tasa de paro en las provincias de Nador y Berkane era del 15\% en 2016, aunque la tasa de "subempleados" (el 11\%) y empleados "no remunerados" (el 15\%) (Haut-Commissariat au Plan du Maroc-Centre National de Documentation, 2016) podrían estar equiparando el desempleo real en ambos lados de la frontera. Esas ratios no casan bien con los importantes crecimientos demográficos que registran Melilla y la provincia de Nador (ambas por encima de las medias estatales), sólo explicables por la frontera entendida como oportunidad, para el intercambio y para pasar a Europa desde África.

En Melilla, en 2018, el sector primario (pesca, distribución de agua y energía) junto con la industria apenas generaban el 3\% del empleo existente, y la construcción ofertaba un 4\%. En la provincia de Nador, por el contrario, el sector primario ocupaba en 2016 al 26\% de los activos y la construcción al 15\%. La industria apenas está representada en Melilla, y en la provincia de Nador es también muy residual, el 9\%, básicamente ocupada en artesanías (textil, productos de cuero y de madera). Por el contrario, en Melilla, el 93\% se empleaba en los servicios, cuando en la provincia de Nador ocupa al 50\%. Siendo la principal actividad en ambos casos, sin duda la fuerte especialización de Melilla obedece a la prestación de servicios más allá de la frontera. En concreto, el comercio (por mayor y por menor) ocupaba al 25\% de los activos en Melilla y sólo al 9\% en la provincia de Nador. En ambos casos, la administración del Estado y los servicios públicos ocupaban un alto porcentaje de activos: $51 \%$ en Melilla y $26 \%$ en la provincia de Nador, sin duda por la influencia de la frontera (defensa, seguridad, control y administración de tránsitos). Los servicios contribuían con el 89\% del total del PIB de Melilla y con el 58\% en la provincia de Nador.

En ambos casos, las empresas comerciales son muy pequeñas, de carácter familiar, donde el propietario constituye, con frecuencia, el único trabajador de la empresa (al menos el único declarado), ayudado

3 La Enquete Nationale sur le secteur informel (Direction de la Statistique. Haut-Commissariat au Plan) 2006-2007, definía así la "actividad económica informal": bajo capital, mano de obra poco cualificada, acceso limitado a los mercados organizados y la tecnología; ingresos bajos e inestables, malas condiciones de trabajo, al margen de las regulaciones legales y de los sistemas formales de protección social y protección laboral. http://www.hcp.ma/downloads/Secteur-informel_tl1887.html 
con frecuencia en su gestión por los demás miembros de la familia: en Melilla, el 53\% de las empresas no cuenta con ningún asalariado, y otro $29 \%$ cuenta con menos de 2 empleados. En esta ciudad, el comercio es, sin duda, la principal actividad económica: en 2018 había 4.426 empresas comerciales, que suponían el 95\% del total de empresas de la ciudad (DIRCE-INE). Al comercio al por mayor se dedicaban $998 \mathrm{em}-$ presas (reflejo del tránsito fronterizo de mercancías) y 3.428 al comercio al por menor, también dedicadas en gran medida al tránsito de mercancía transfronteriza, mediante la compraventa de muy pequeñas partidas, génesis del peculiar y consentido contrabando a pequeña escala.

Figura 7. Suelo ocupado por construcciones en Melilla (2016) y Plan Movilidad (2015) que propone conectar las áreas suburbanas fuera de la frontera

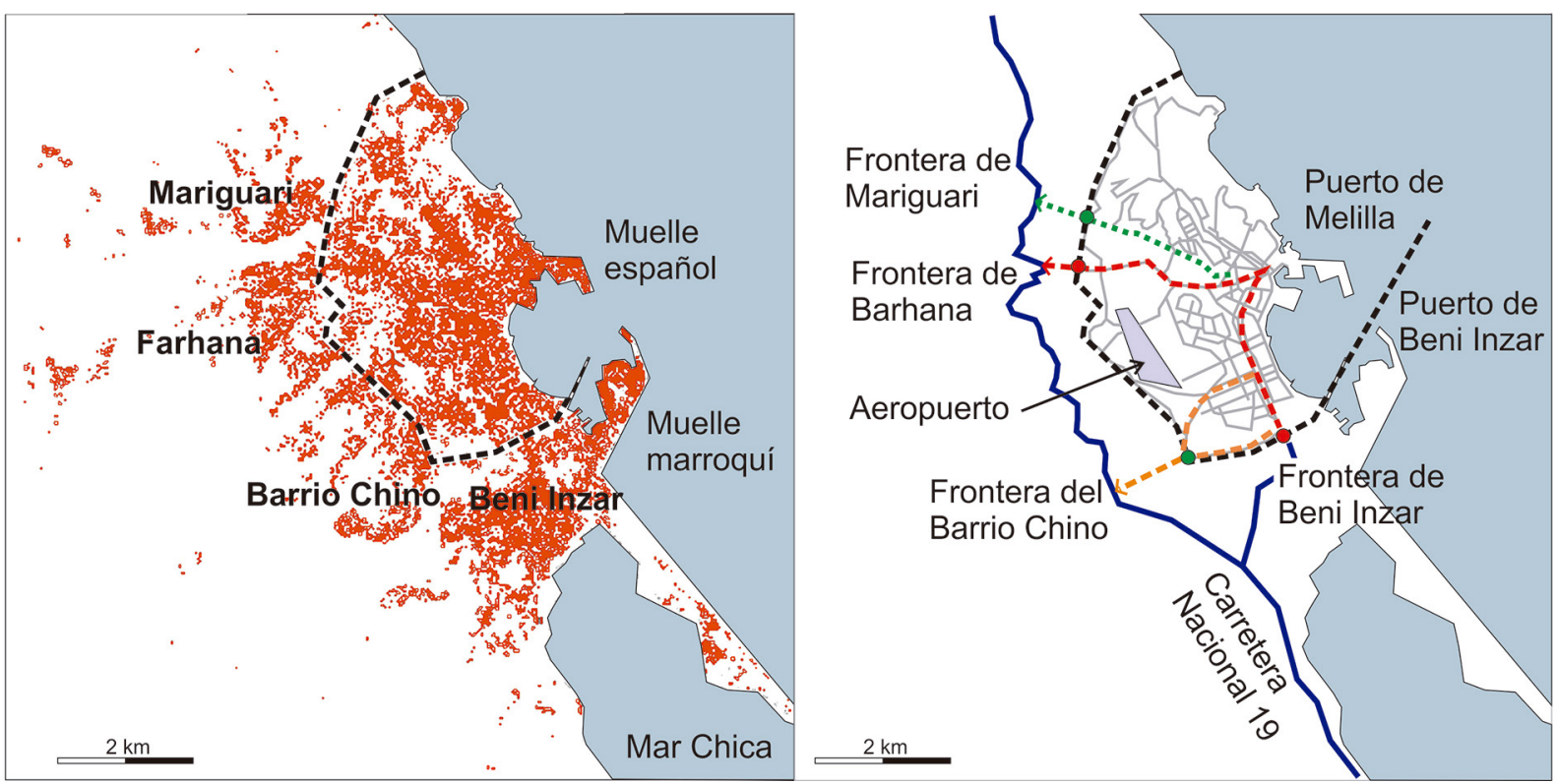

Fuente: Global Human Settlement (European Commission, 2016). Plan de Movilidad Urbana de Melilla (Ciudad Autónoma de Melilla, 2015). Elaboración propia

\subsection{La identificación del continuo urbano de la región transfronteriza}

El marco del área de influencia de Melilla no ha sido todavía establecido. Desde España, el Atlas Estadístico de las Áreas Urbanas Españolas (Ministerio de Fomento, 2017) ofrece una aproximación sesgada. Melilla es considerada una de las grandes áreas urbanas, contando exclusivamente con su municipio y, por tanto, excluyendo cualquier relación con el resto del territorio marroquí de Nador. En Marruecos, la única delimitación oficial es la del perímetro de las comunas urbanas o perímetro municipal, entendido como delimitación para la aplicación de las normas administrativas (es decir, sin vocación analítica). Los proyectos de identificación de áreas urbanas europeas, como NUREC (European Union, 2016) o ESPON (European Union, 2013, 2016), se han centrado más en la Europa continental que en las particularidades de estas ciudades periféricas en otros continentes. También el proyecto CORINE Land Cover (Ministerio de Fomento, 2018) se centra exclusivamente en los usos del suelo dentro del límite municipal de Melilla.

Por tanto, se propone aquí una aproximación conforme con los métodos de delimitación de áreas metropolitanas y áreas urbanas, mediante la utilización de datos sectoriales (demográficos, económicos, funcionales — tiempos de desplazamiento, movilidad por trabajo-y morfológicos) (Feria, 2010; Salom y Albertos, 2014; Duarte y Troncoso, 2012), obtenidos con dificultad, bien por la inexistencia de fuentes comparables, bien por su carácter estratégico y reservado (frontera caliente). Con ellos, las cartografías permiten establecer algunas delimitaciones de aproximación al fenómeno de la configuración de un área urbana jerarquizada en torno a Melilla.

\subsubsection{Los mapas de densidades y las tendencias hacia la conurbación}

Se han manejado los indicadores de densidad de habitantes que ofrece el Centre for Advanced Spatial Analysis (2018). También los datos de población identificada por la Comisión Europea en su portal Global 
Human Settlement, que recoge la evolución de la densidad de población entre 1975 y 2016. En la Figura 7 se observa el desbordamiento de la valla fronteriza por todo el perímetro de Melilla, con múltiples ejes radiales que siguen las cañadas y barrancos, suelos de elevada pendiente y baja calidad agrícola. Se han desarrollado a partir de los cuatro pasos fronterizos habilitados: el de Mariguari y el del Barrio Chino, con menos de 1.000 personas diarias, y los de Farhana (5.000 personas y 1.300 vehículos diarios) y Beni Inzar (14.000 personas y 2.500 vehículos diarios), pero también sobre otros caminos y sendas rurales de menor importancia sin acceso directo a Melilla, convergentes en la zona de servidumbre de la valla, que funciona como "camino de ronda" hacia lo cuatro pasos habilitados.

Figura 8. Evolución de la densidad demográfica (habitantes $/ \mathrm{km}^{2}$ )

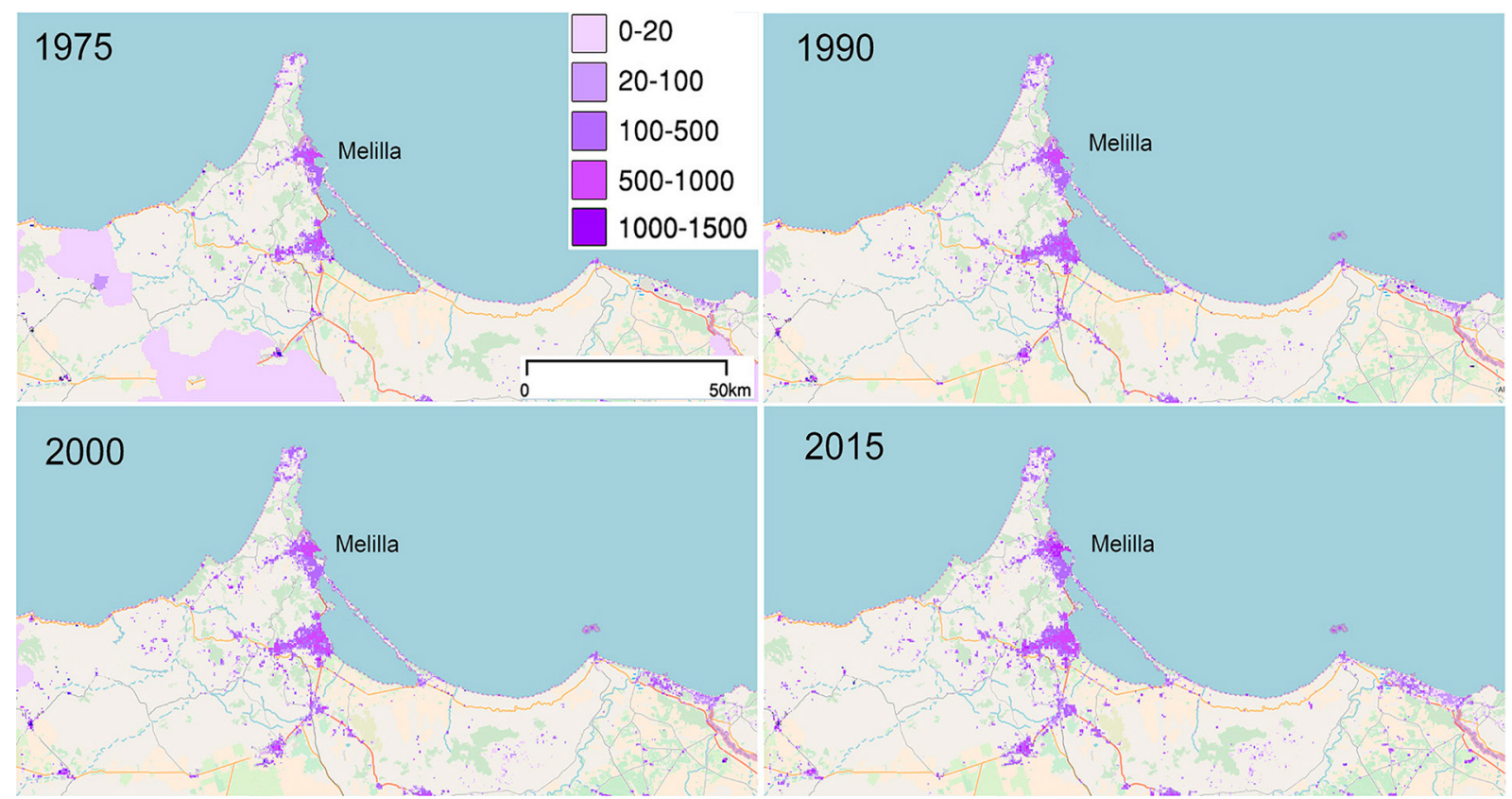

Fuente: Global Human Settlement (European Commission, 2016). Elaboración propia

Figura 9. Evolución de la mancha urbana (compacta y dispersa) a lo largo de la carretera Melilla-Nador

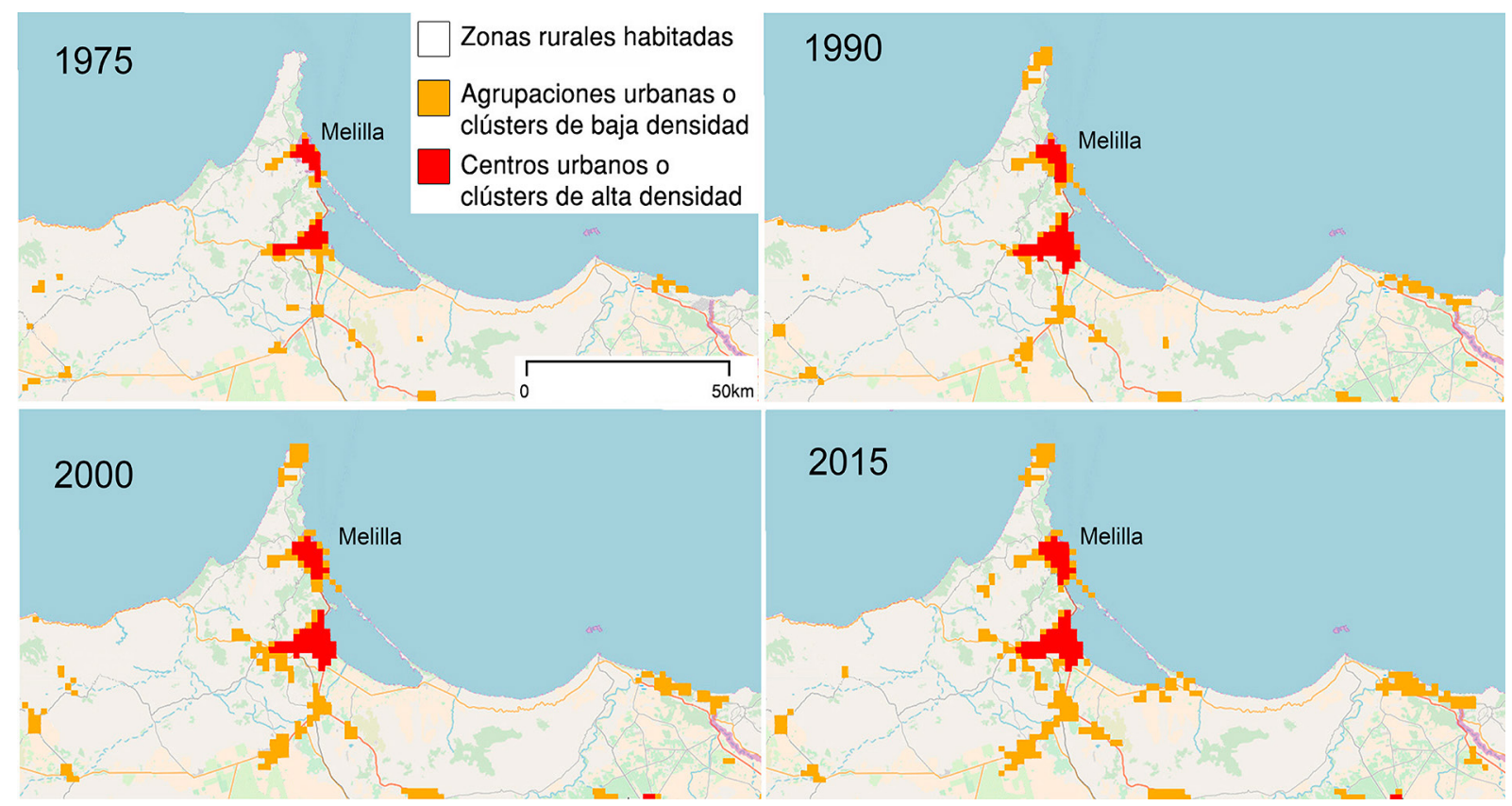

Fuente: Global Human Settlement (European Commission, 2016). Elaboración propia 
En la Figura 8, los mapas de evolución de la densidad demográfica evidencian la importancia del eje Melilla-Nador y cómo Selouane se ha ido incorporando paulatinamente al eje de crecimiento. En la Figura 9, se observa la tendencia hacia la conurbación por la ampliación de los perímetros urbanos de las principales ciudades, consideradas cluster por el atlas de Global Human Settlement: áreas de alta y baja densidad, que se desparraman en racimo por el territorio. El cluster de baja densidad de 2015 dibuja la conurbación, que se expandiría más allá de Selouane, por las comunas rurales de ese municipio, merced a la accesibilidad que ofrecen las principales vías de comunicación.

En general, del análisis se desprenden tres aspectos destacados: la sucesiva ocupación de todo el perímetro externo de la ciudad de Melilla, la continuidad del hábitat, a pesar de la frontera (soslayando el problema de la valla) y la configuración de un continuo urbano, que se expande hacia el sur por las tierras llanas, productivas — de vocación agrícola - y bien comunicadas, que ofrece la posibilidad de acceder al comercio formal e informal generado en la frontera, como fuente alternativa de ingresos.

\subsubsection{La conurbación a través del análisis de densidad de intersecciones viarias y de continuidad de usos urbanos}

A partir de los datos del atlas Global Human Settlement, referidos a 2015, en la Figura 10 se ha cartografiado la mancha urbana tal cual se percibe por los sensores remotos, distorsionada por la importancia del hábitat rural disperso (buena parte de la mancha rosa). Para evitar esa alteración, se ha procedido a utilizar métodos estadísticos, como el que considera las intersecciones viarias —encrucijadas- como un fiel exponente del proceso de urbanización (Borruso, 2003; Salom y Albertos, 2014). A partir de 40 intersecciones por $\mathrm{km}^{2}$ podría considerarse como "continuo urbano", siempre que las áreas construidas estén unidas o separadas por espacios inferiores a $1 \mathrm{~km}$ de distancia (unos 12 minutos andando). La Figura 11 recoge los resultados de este análisis, que define una nube continua de nodos entre Melilla y Monte Arruit. En ese sentido, la distancia entre edificaciones puede ser ponderada en la cartografía, si se considera la vocación del suelo todavía no ocupado — suelo residual — entre manchas de usos urbanos — residencial, industrial y terciario-, siempre que los vacíos sean inferiores a $1 \mathrm{~km}$ de distancia. Con esa ponderación se ha cartografiado la Figura 12, donde se aprecia que desaparecen las discontinuidades entre Nador, Selouane y Monte Arrouit, y que la conurbación parece extenderse más allá de las áreas estrictamente conectadas (por el peso del hábitat rural disperso en la síntesis cartográfica). En la Figura 13 se han considerado conurbados espacios separados hasta con $2 \mathrm{~km}$ de distancia, siempre que los usos fuesen industriales y terciarios, al considerar que esa distancia puede ser normal en ese tipo de instalaciones. No se ha contemplado cuando los usos han sido residenciales. Aunque el método ha sido validado en otras partes, se considera que, en este caso, resulta excesivo, por cuanto la cartografía del espacio supuestamente conurbado va más allá de la realidad empírica. Aunque el mapa tiene la virtud de mostrar claramente los vectores y tendencias de crecimiento.

Figura 10. La mancha urbana sin ponderaciones

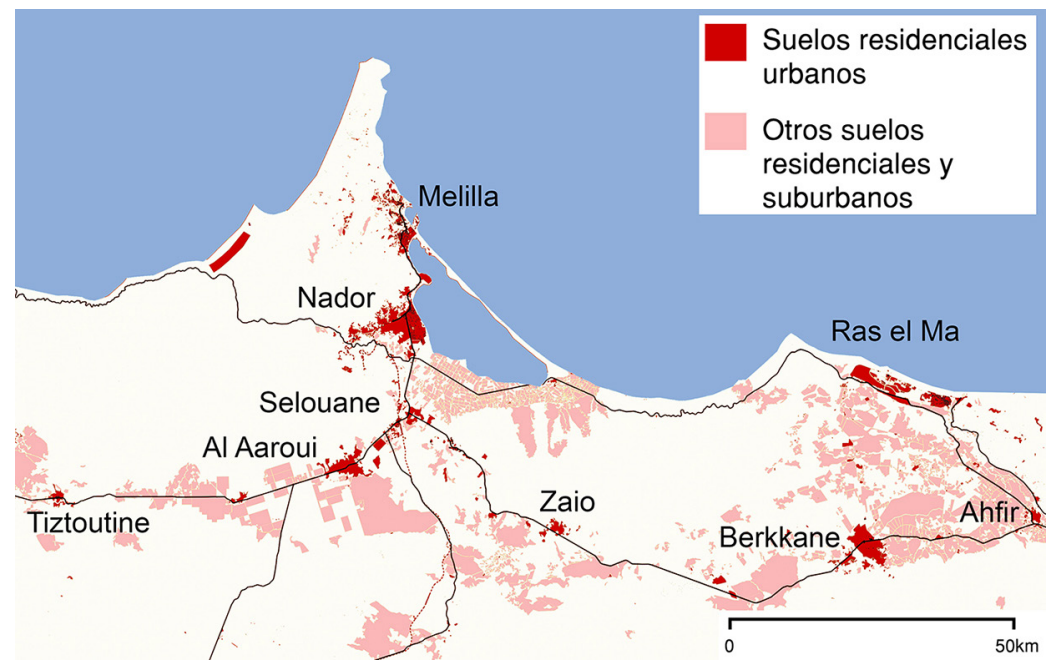

Fuente: Global Human Settlement (European Commission, 2016). Elaboración propia 
Figura 11. La mancha urbana según el método de intersecciones de la red viaria

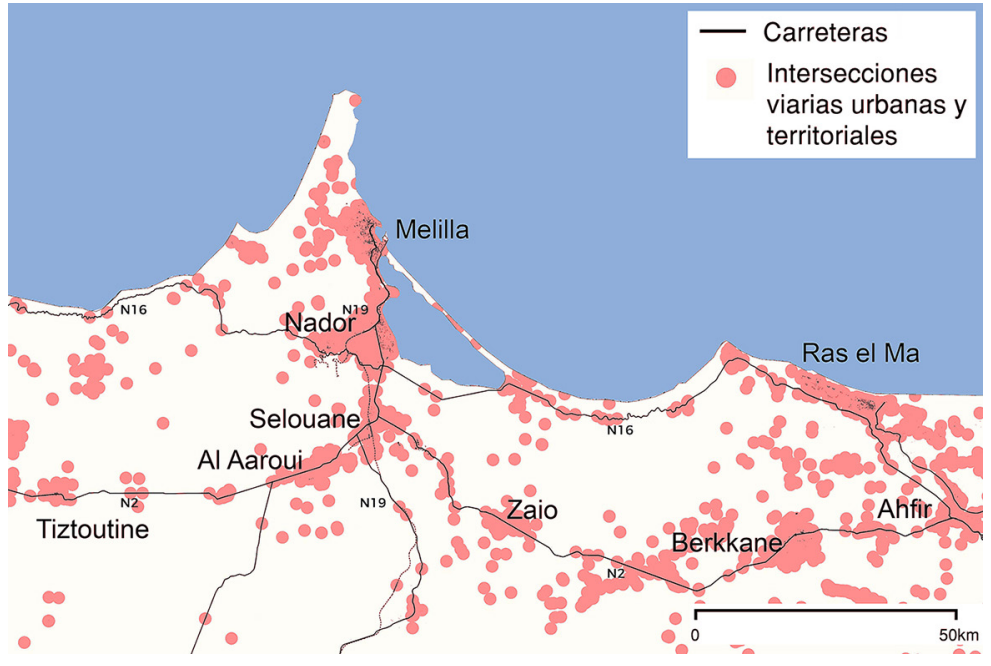

Fuente: Global Human Settlement (European Commission, 2016). Elaboración propia

Figura 12. La mancha urbana ponderada en $1 \mathrm{~km}$ de ruptura

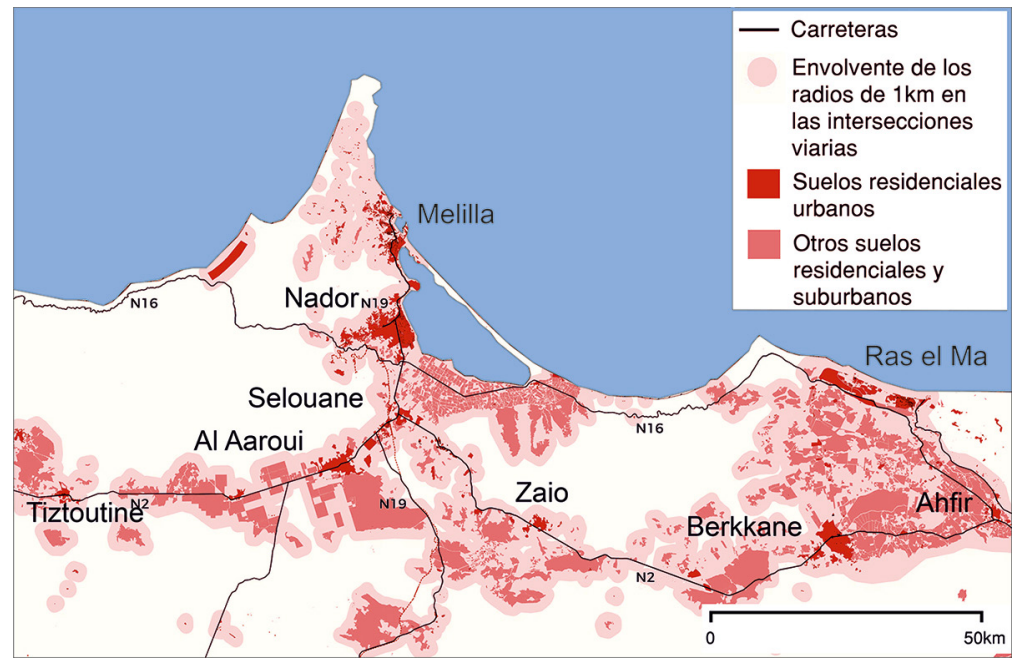

Fuente: Global Human Settlement (European Commission, 2016). Elaboración propia

Figura 13. La mancha urbana ponderada en $2 \mathrm{~km}$ de ruptura

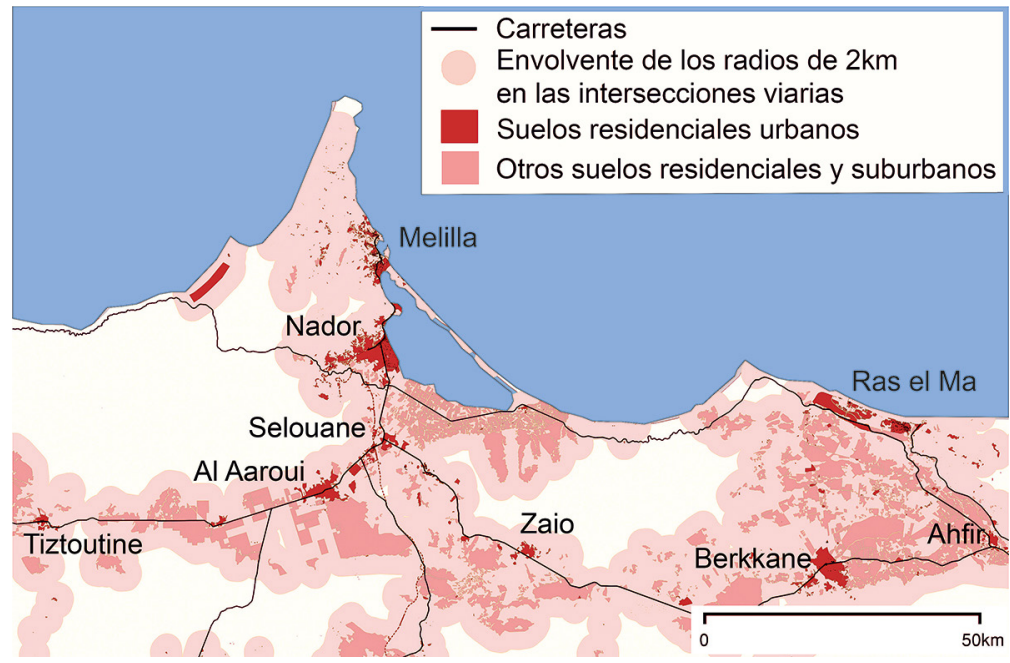

Fuente: Global Human Settlement (European Commission, 2016). Elaboración propia 
Los resultados evidencian la continuidad compacta norte-sur entre las ciudades de Melilla, Nador y Selouane, y de forma tendencial hasta la ciudad de Monte Arrouit, a unos $40 \mathrm{~km}$ de distancia de Melilla. A partir de Selouane, los indicadores presentan más rupturas y discontinuidades, pero apuntan hacia la configuración futura de un arco Selouane-Zaio-Berkkane-Ahfir en la frontera con Argelia, impulsado por la economía de frontera. Podría concluirse que la accesibilidad y vecindad son aspectos clave de las tendencias hacia la conurbación. Pero insuficientes de no mediar otros destacados aspectos, como el de una fuerte especialización económica dependiente de la frontera.

\subsubsection{Hacia una estructura policéntrica}

De los análisis precedentes se desprende que la región transfronteriza tiende hacia un evidente policentrismo. Los flujos de mercancías y pasajeros estructuran un vigoroso eje de comunicaciones - carretera CN19-, con tres destacados focos de actividad - Melilla, Nador y Selouane-. En él, el índice de potencial económico destaca la jerarquía de Nador y Melilla. Esto es, la frontera desigual y los intercambios selectivos van definiendo la especialización funcional del sistema urbano transfronterizo, que incorpora en su ámbito de influencia, otros núcleos complementarios, con base agrícola, que también gravitan sobre un dinámico y complejo sector servicios. Los análisis de tendencia de densidades apuntan hacia varias conurbaciones, sobre la $\mathrm{CN} 19$, más evidentes cuanto más próximas a la frontera.

Como técnica de trabajo, hemos enfrentado la zona analizada con los modelos generados por la complementariedad entre ciudades, con la desarticulación de las fronteras intraeuropeas, ya que el caso estudiado recuerda, por su configuración morfológica — conurbaciones e intersticios- y funcional -especialización en torno a la economía de frontera - a una "mega ciudad regional policéntrica" (Hall y Pain, 2006). Pero se debe insistir en que la singularidad de Melilla y su frontera escapan claramente al modelo, ya que el concepto, definido para las regiones urbanas europeas de ciudades que, en igualdad de condiciones, colaboran, se complementan y prosperan, no puede aplicarse a este espacio política y socialmente fracturado. Con todo, los elementos que sustentan ese modelo pueden vislumbrarse en la región transfronteriza analizada, por eso se manejan aquí como factores estructurantes. Así, parece clara la existencia de una cuenca de trabajo compartida, de unos flujos económicos intensos, de un recurso común compartido - la frontera entendida como oportunidad económica - y de una división funcional del mercado de trabajo que promueve una cierta especialización complementaria en el sistema urbano analizado, en el que Melilla aparece como el lugar de los servicios centrales, finanzas (las plusvalías de las grandes transacciones formales se quedan aquí), servicios especializados, comercio extra-ordinario y ordinario: se propone construir una gran superficie comercial justo en la frontera para reforzar el papel de gran bazar de Melilla. Por su parte, Nador se erige como la ciudad industrial, mientras las demás ciudades de la red se hallarían subordinadas, con funciones agrícolas y de almacén de mano de obra.

Figura 14. Análisis cutoff del sistema urbano transfronterizo, 2016

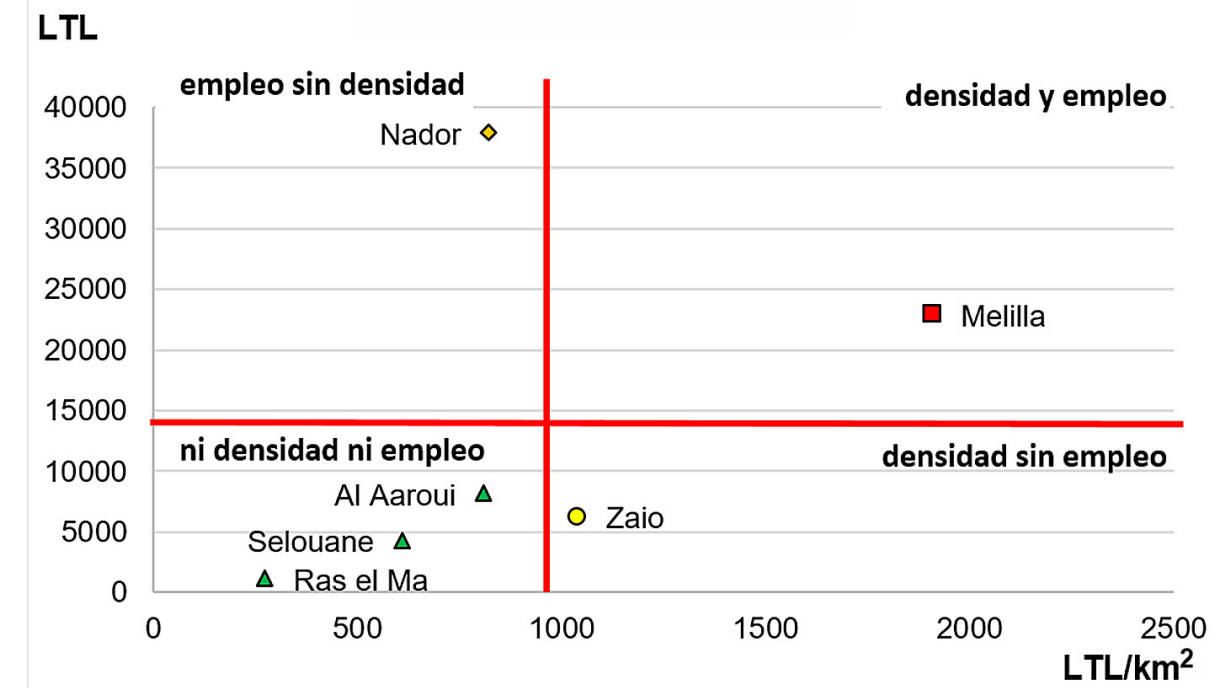

Fuente: INE (2016), Haut-Commissariat au Plan (2016); Global Human Settlement (2015). Elaboración propia 
La técnica del cutoff permite indagar en la composición cualitativa de un sistema urbano que, en apariencia, como es el caso, mantenga las características expuestas (Duarte y Troncoso, 2012). Se trata de cuantificar la densidad de lugares de trabajo localizados (LTL) por kilómetro cuadrado de suelo artificializado. En la región transfronteriza analizada, con los datos de las respectivas encuestas de trabajo de cada país (INE, 2016 y Haut-Commissariat au Plan, 2016) y las superficies estimadas a partir de Global Human Settlement, se ha procedido al análisis de los empleos localizados en suelo urbano (esto es, de los sectores secundario y terciario), con los resultados que ofrece la Figura 14. A partir del umbral definido por el propio sistema urbano, se observa la jerarquía de Melilla, como núcleo de empleo y alta densidad, el destacado papel de Nador, con mayor empleo pero menor densidad, y la función secundaria de las demás ciudades importantes de la red.

\subsection{Indicadores sociales de jerarquía transfronteriza}

La jerarquía funcional de Melilla sobre su entorno se ejerce, además, por otros aspectos cualitativos. Entre ellos, por su importancia y significación, se analiza aquí el sistema sanitario. Para el conjunto de la provincia de Nador, en 2016 había 164 médicos y un total de 467 camas de hospital, lo que supone unas ratios de 3.448 habitantes/médico y 1.211 habitantes/cama, mientras en Melilla, las ratios eran de 246 habitantes/médico y 508 habitantes/cama. La "tarjeta sanitaria" limitó, entre 2012 y 2018 el "derecho legal" a la asistencia sanitaria en el sistema público de España, sin embargo, la utilización siguió siendo importante, merced a la laxitud en los controles y a la asistencia a través del sistema de urgencias (servicio universal y sin restricciones en España). El Hospital Comarcal de Melilla (público), en sus memorias anuales contempla la prestación de esos servicios al contingente de personas que atraviesan la frontera a diario y que también reciben asistencia sanitaria (Instituto Nacional de Gestión Sanitaria [INGESA], 2018): en 2016 asistió a un total de 15.941 pacientes extranjeros, el 72\% a través del servicio de urgencias, utilizado sobre todo para asistencia de partos de mujeres con visado procedentes de la provincia de Nador: 1.772 mujeres en ese año. Se estima que las urgencias atendidas serían las normales para una ciudad de unos 350.000 habitantes, cuando la población real de Melilla es la cuarta parte (INGESA, 2018).

Otros indicadores sanitarios públicos y privados refuerzan esa atracción: 22 dentistas en la provincia de Nador (con 565.426 habitantes en 2014), frente a 34 en Melilla (con 85.584 habitantes ese año); una farmacia en Nador por cada 63.000 habitantes, frente a los 5.000 habitantes de media en Melilla. Un total de 440 trabajadores sanitarios (enfermeros y otros) en la provincia de Nador, frente a los 650 trabajadores sanitarios de Melilla. Son datos cuantitativos y, a la vez, cualitativos de la profunda asimetría de la frontera, expresada también en la Figura 15, que cartografía la disparidad en los presupuestos municipales.

Figura 15. Presupuesto municipal de gasto por habitante 2014 (euros)

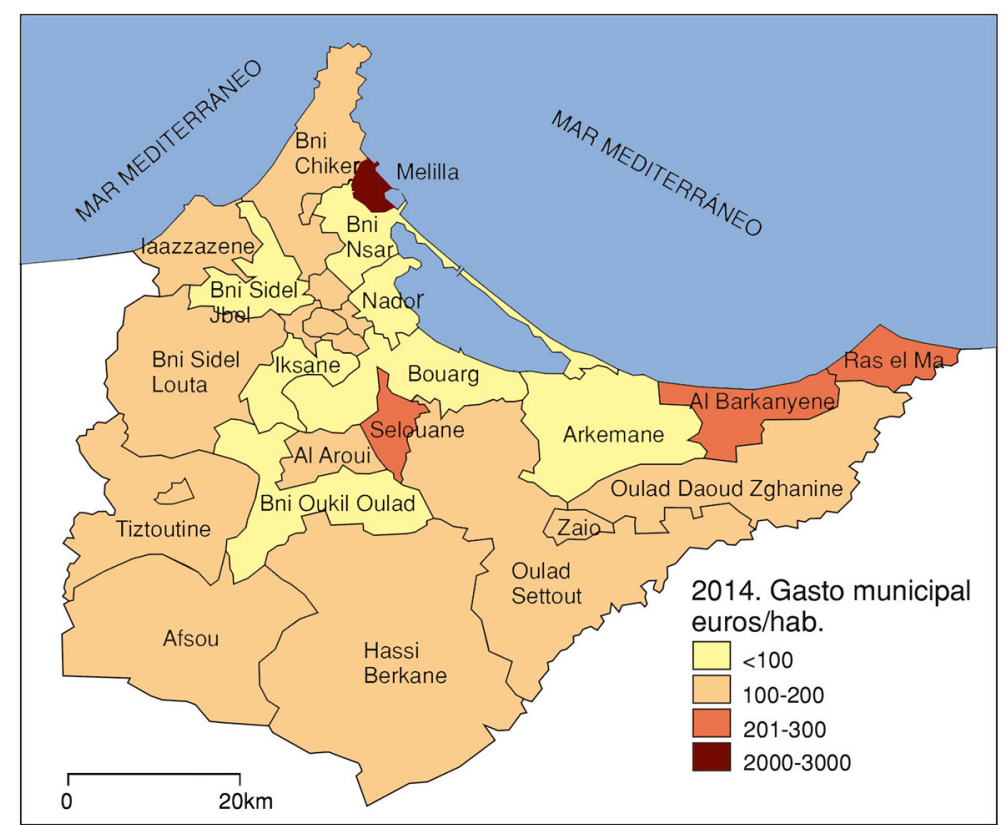

Fuente: Haut-Commissariat au Plan du Maroc-Centre National de Documentation, 2014; INE, 2014. Elaboración propia 


\section{Discusión de resultados}

\subsection{La frontera asimétrica como oportunidad}

Aun cuando los temas de análisis sobre esta frontera son múltiples y los enfoques muy variados (como muestra la bibliografía existente sobre aspectos sociales, legales y políticos), se ha centrado la discusión en los aspectos verificados en los análisis efectuados, conducentes a identificar, cuantitativa y cualitativamente, la vinculación funcional y la forma urbana resultante en la región transfronteriza. En ese sentido, cuestión esencial ha sido la de identificar la frontera como oportunidad. Bien que con los matices que introduce Sohn (2014) al señalar la asimetría en las condiciones de uno y otro lado como motor de los procesos de integración económica, pero no social, ni territorial. En esta frontera no existen planes para la integración, antes al contrario (conforme con estrategias de carácter estatal en ambos países). Por ello, son los actores individuales los que desarrollan prácticas que aprovechan la frontera como recurso, con la permisividad de los Gobiernos de ambos países. Se comprueba aquí la estrategia europea en sus fronteras exteriores denunciada por Ferrer (2008) que, por un lado, suaviza algunos controles - acceso de mano de obra y pequeño contrabando de mercancías—- al tiempo que refuerza otros — defensa, seguridad-, señaladas como parte interesada de una "industria del control migratorio en el Sur" con presupuestos millonarios que manejan unas pocas empresas privadas (Rodríguez y Fanjul, 2017). Es práctica extendida en las fronteras que separan condiciones socioeconómicas asimétricas en todo el Mundo, como ponen de manifiesto Alegría (1992, 2000 y 2008) al estudiar las relaciones fronterizas entre Estados Unidos y México, y Dilla (2015) y Dilla y Breton (2018) al extender el análisis de caso a las ciudades latinoamericanas.

La asimetría en la región transfronteriza es patente respecto de las condiciones económicas, pero no tanto en las culturales y sociales. Las estimaciones actuales sobre la cifra de musulmanes que viven en Melilla se basan en el recuento de los apellidos inscritos en el Padrón y en los nombres de la población escolarizada. A partir de ahí se considera que un porcentaje del $50 \%$ debe ser la proporción más ajustada a la realidad, para el conjunto de los ciudadanos, si bien el porcentaje se eleva hasta el $60 \%$ entre la población infantil. De hecho, desde 1995, el colectivo cultural musulmán se aglutina políticamente en el partido Coalición por Melilla, que en las elecciones de 2019 obtuvo el 32\% de los votos, cuando en 1995 solo logró el $15 \%$. Por ello resulta más patente la artificialidad de la frontera y llamativa la ausencia de planes de integración territorial y gobernanza conjunta. Circunstancia que aproxima el caso de Melilla a la hipótesis que manejan Dilla y Breton (2018), cuando señalan que las fronteras se utilizan en la actualidad como mecanismos disciplinarios de flujos para mantener la desigualdad y, de ese modo, hacer rentable económicamente la frontera. En Melilla, no sería tan importante el filtro étnico cultural (concepto histórico de frontera), como el clasista (Kearney, 2008). En ese sentido, los indicadores económicos parecen mantener la asimetría competitiva: el diferencial en renta per cápita general entre España y Marruecos se ha mantenido en valores similares entre los años 2000 y 2017: el PIB per cápita de Marruecos suponía el $9,4 \%$ y el 10,8\% respectivamente del de España. En concreto, el PIB per cápita de la región Oriental entre 2013 y 2016 (según los datos disponibles) suponía el 70\% y el 71\% respectivamente del PIB per cápita de Marruecos, y el empleo informal en la región, que en 2000 suponía el 8\% del total del País, en 2014 se había elevado hasta el 9\%.

En cualquier caso, se trata de una relación interfronteriza muy alejada de las recomendaciones expresadas por las estrategias de cohesión europeas (Organización para la Cooperación y el Desarrollo Económicos [OECD], 2013), desarrolladas, entre otras, por los programas INTERREG (Martín-Uceda y Vivas, 2018), las Agrupaciones Europeas de Cooperación Territorial o los proyectos ESPON (European Union, 2013 y 2016), analizados también por Bassols y Correa (2017) y Feliu, Berzi, Martín-Uceda, Saberi y Vivas (2018) o Giband y Rufí (2018), conforme con el gran interés científico que suscita el proceso de "desfronterización europea", respecto de las oportunidades de colaboración entre ciudades fronterizas, sobre bases de complementariedad y competitividad, que trascienda la actual competencia entre municipios vecinos separados por una frontera. Es proceso que está alterando también las formas urbanas de las ciudades fronterizas europeas, con tendencias analizadas con modelos que hablan de "ciudades binacionales" y "mega ciudad regional policéntrica", donde los beneficios tienden a repartirse con equidad a uno y otro lado de la frontera.

\subsection{Las formas urbanas transfronterizas}

De los análisis de densidades se comprueba la tendencia hacia una macro conurbación, concretada ya en el eje Melilla-Nador-Selouane. Se observa en este caso los factores que describe Jessop (2004) cuando 
analiza el cambio del concepto de frontera, desde un borde hacia un lugar de intermediación, que es posible por la capacidad del capital para transformar territorios, por el nuevo orden político internacional, muy especial en el caso España-Marruecos, que relativiza el control fronterizo y, sobre todo, por el dinamismo y emprendedurismo de los agentes locales (en diferentes escalas) a uno y otro lado de la valla fronteriza. Las intensas relaciones personales entre las comunidades estarían definiendo una región funcional transfronteriza, que se plasma en una fuerte concentración del hábitat (de la mano de obra) en el principal eje de acceso a la frontera, la Carretera Nacional 19, y alrededor del trazado de la valla (Figura 7). Más allá de Selouane, el tejido urbano se fragmenta, la conurbación desaparece, pero se mantiene la complementariedad funcional.

En esa conurbación real, se da la interacción, pero también el conflicto, ya que las fluidas "relaciones transfronterizas" se hallan supeditadas a las tensas "relaciones transnacionales (Dilla, 2015). Así, aunque conurbada la forma, no podría definirse el conglomerado urbano a uno y otro lado de la valla como una "metrópolis transfronteriza", concepto que acuño Herzog (1990) para el caso de Tijuana y San Diego, ciudades conurbadas y separadas también por una valla. Como apunta Alegría (2000 y 2008) para el caso de las ciudades conurbadas a uno y otro lado de la frontera entre México y Estados Unidos, tampoco el eje Melilla-Nador-Selouane ofrece una "ecología urbana única", ni una integración del mercado laboral (a pesar de que se comparte) en igualdad de condiciones y la gestión urbana es muy diferente a uno y otro lado (Figura 7): la planificación urbana de Melilla ofrece estándares urbanísticos (infraestructuras, equipamientos y servicios) muy contrastados con los de las otras ciudades conurbadas.

En opinión de Dilla (2015) tales conurbaciones, más que como "metrópolis transfronterizas", deben ser conceptualizados como "complejos urbanos transfronterizos". Sería el caso analizado, donde las ciudades comparten un mismo entorno, marginal en los flujos de Marruecos (Troin, 2002) y en los de España, donde algunas ciudades se han conurbado y otras comparten cercanía geográfica. Sobre ellas se ha desarrollado un corredor transfronterizo (España-Marruecos-Argelia), cuyos intensos flujos definen la fisonomía espacial y una cierta especialización funcional: servicios especializados y finanzas en Melilla, industria en Nador, agricultura en el resto de ciudades, confinadas por la jerarquía de la red a meros almacenes de mano de obra. Por su potencia, Melilla y Nador desarrollan importantes hinterland y suburbios, que conviven en el entorno ecológico de la frontera, y son complementarios, pero que no llegan a una integración urbana propiamente dicha. Ambos lados de la frontera se necesitan, existe una fuerte interdependencia económica, con la percepción de que la clausura de los flujos primarios en la frontera empeoraría el estado de las cosas (de los negocios, pero también del consumo de servicios y de la calidad de vida).

El conglomerado urbano transfronterizo evoluciona de forma orgánica, sin propuestas de integración, y sin directrices de gobernanza territorial, con una escala local de decisiones siempre supeditada a las tensas relaciones internacionales. Durante los trabajos de redacción del plan general de Melilla, todas las propuestas urbanísticas del equipo debían supeditarse a los intereses estratégicos de la defensa militar de la ciudad (volúmenes, densidades, servidumbres de cuarteles y de la propia valla). Pero también en la escala local aflora el conflicto: las mismas propuestas urbanísticas (y en concreto el tipo de viviendas, la organización de los barrios y las dotaciones urbanísticas de equipamientos y servicios), chocaban con los intereses de la comunidad musulmana de la ciudad, cuyos próceres veían en el despliegue urbanístico "occidental" una seria amenaza hacia su cultura y modos de vida.

Algo similar sucede al otro lado de la frontera, donde hay mayor permisividad para ocupar la franja de servidumbre de la valla, en cierta medida como un "dejar hacer" provocativo frente a la antigua metrópoli colonial. En esta parte de la frontera, el crecimiento espontáneo de la forma urbana tiene larga tradición. Troin, (2002) señala el aislamiento del sistema urbano de la provincia de Nador y su configuración en nebulosa alrededor de la ciudad de Nador. Pone de manifiesto cómo los capitales generados por la emigración y por la frontera (economía formal e informal) han desarrollado, al menos desde los años 1990, nuevas formas urbanas híbridas, entre occidentales y tradicionales, que han afectado el urbanismo tradicional. El flujo transfronterizo y los beneficios marginales han promovido la motorización de la población, el abandono paulatino de los viejos y constreñidos centros urbanos y la elección de las principales vías de comunicación como espacio para el nuevo urbanismo, en forma de grandes ejes ruteros donde se alinean viviendas, talleres, almacenes, fábricas y servicios. Junto a desarrollos urbanos inspirados en modelos occidentales - a veces ostentosos, importados por los propios emigrantes- aparecen grandes aglomeraciones de chabolas y de otras viviendas, todas caracterizadas por su ilegalidad. Sultán (2002) señalaba que el hábitat clandestino es la forma dominante en Nador. 
Se ha llegado de ese modo a las conurbaciones cartografiadas (Figuras 10 a 13), todas sin planificación previa, que ahora la Agence Urbaine de Nador (2019) intenta ordenar mediante el desarrollo de diferentes planes locales de urbanismo (desde los años 2010), coordinado con un plan maestro que afecta al $40 \%$ del territorio y al $80 \%$ de los habitantes de la provincia. El plan maestro, ahora en fase de elaboración, lejos de procurar la integración con Melilla, desarrolla estrategias competitivas frente a las ventajas de la ciudad española, como son la ampliación del aeropuerto y la construcción de un nuevo puerto comercial, y otras para captar inversiones por descentralización desde España (incluso desde Melilla), como suelo industrial, desarrollos turísticos y equipamientos específicos. El proceso recuerda al de las maquilas mexicanas con inversiones norteamericanas (Mendoza, 2010).

Al estudiar los casos de fronteras intraeuropeas, Sohn (2014) señalaba la existencia de dos grandes modelos: uno guiado por grandes proyectos territoriales de transferencia y cohesión, bajo buenas prácticas coordinadas de gobernanza, y otro, que denomina "modelo geoeconómico", basado en la explotación de beneficios entre situaciones asimétricas, que parece ser el caso del conglomerado urbano transfronterizo analizado.

\section{Conclusiones}

Los análisis cartográficos de continuidad urbana evidencian la configuración de una gran conurbación transfronteriza, apoyada en el intenso intercambio terrestre de personas y mercancías. La frontera presenta el aspecto de filtro selectivo que endurece los controles en los aspectos relacionados con la defensa y seguridad nacional, y los relativiza frente al paso de mano de obra y al menudeo de mercancías. Los acuerdos interestatales que, por un lado, frenan la integración territorial, por otro favorecen la oferta de servicios especializados de Melilla (privados y públicos, como la sanidad y la educación) sobre un amplio territorio de influencia, hinterland que consume la oferta de Melilla y ofrece mano de obra y materias primas (alimentos) y propone, para el futuro, la oferta de suelo para acoger las inversiones descentralizadas desde España. Tanto el comercio formal como el informal constituyen el motor de la economía de ambos espacios, donde alcanzan significación parecida a la del gasto en defensa, administración y seguridad (el otro fundamento de las economías de estos enclaves territoriales), de unos territorios alejados y marginales respecto de sus propios Estados, pero que se necesitan y complementan entre sí. De ese modo, las relaciones entre agentes locales tejen densas redes complementarias, que siguen repartiendo de forma desigualitaria los beneficios y tienden hacia una cierta especialización funcional del sistema urbano definido, en el que Melilla se erige como centro de servicios especializados, Nador como cabecera industrial en desarrollo y el resto de ciudades cómo ámbitos claramente subordinados. En ese sentido, se comprueba la existencia de un modelo geoeconómico de explotación de la frontera, que favorece el flujo de grandes inversiones y los beneficios marginales de buena parte de la población. La forma en que esas dinámicas se plasman en el territorio, conurbación e intersticios que tienden a la conurbación, sin desarrollar programas de integración conjunta. Al contrario, cada una de las cabeceras del sistema - Melilla y Nador - proponen planes por separado para seguir captando selectivamente los beneficios de la frontera. Se confirma también la hipótesis de que la forma urbana desarrollada, y tendencial, se asemeja al modelo de complejo urbano transfronterizo, donde diversas ciudades, conurbadas o vecinas, desarrollan redes de complementariedad selectiva y en competencia, que mantienen las desigualdades. Puede, por ello, considerarse un estudio de caso que refuerza las teorías y modelos de ciudades en fronteras asimétricas, muy características de América Latina (Herzog y Song, 2014; Dilla y Bretón, 2018), pero que también se dan en las antiguas colonias europeas en Asia, como Hong Kong (Jessop y Sum, 2000) y Taiwan (Chou y Lin, 2007).

El interés y la novedad de este trabajo radica en el análisis integrado de la región transfronteriza, no realizado hasta ahora ni desde España, ni desde Marruecos, pese a la abundancia de trabajos sectoriales — sobre todo sobre movimientos migratorios-, para intentar conocer su dinámica y alcance. Su aplicabilidad se concreta en identificar el área vinculada, los flujos existentes y la necesidad de elaborar planes conjuntos de gobernanza e integración, de unas ciudades forzadas a entenderse, pese a las tensiones de los Estados a los que pertenecen, lo que plantea nuevas líneas de trabajo. Puede ser método de análisis aplicable al conocimiento - y para las propuestas de ordenación — de otros espacios transfronterizos de alta desigualdad. 


\section{Referencias}

Agence Urbaine de Nador (2019). Schéma Directeur d'aménagement Urbaine du grand Nador. Recuperado de http://www.aunador.ma/def.asp? codelangue=23\&id_info=1451

Alegría, T. (1992). Desarrollo urbano en la frontera México-Estados Unidos. Recuperado de https:// estudiosdemograficosyurbanos.colmex.mx/index.php/edu/article/view/896

Alegría, T. (2000). Juntos, pero no revueltos: Ciudades en la frontera México-Estados Unidos. Revista Mexicana de Sociología, 62(2), 89-107. https://doi.org/10.2307/3541360

Alegría, T. (2008). ¿Existen las metrópolis transfronterizas? En H. Dilla (Ed.), Ciudades en la frontera (pp. 127-167). Recuperado de https://www.academia.edu/8217411/Ciudades_en_la_frontera

Anderson, J. (2001). Theorizing state borders:'politics/economics' and democracy in capitalism. Recuperado de https://www.qub.ac.uk/research-centres/CentreforInternationalBordersResearch/Publications/ WorkingPapers/CIBRWorkingPapers/Filetoupload,174417,en.pdf

Aziza, M. (2006). La frontiere de Nador-Melilla, une frontiere européene en terre marocaine. Analyse des relations transfrontalieres. Workhop 'Le Rio Bravo Mediterranéen: les regions frontalieres a l'heure de la mondialisation. Recuperado de https://journals.openedition.org/mediterranee/

Banco Mundial (2018). PIB (US\$ a precios actuales). Data Banco Mundial. Recuperado de https://datos. bancomundial.org/indicador/NY.GDP.MKTP.CD

Barras, R. \& García, D. (2015). Hacia un nuevo y diferente" Flanco Sur" en el Gran Magreb-Sahel. Revista UNISCI, (39), 11-46. https://doi.org/10.5209/rev_RUNI.2015.n39.51813

Bassols, N. \& Correa, J. R. (2017). Fronteras europeas: De lo histórico a lo cotidiano. Estudios fronterizos, 18(35), 131-149. https://doi.org/10.21670/ref.2017.35.a7

Boletín Oficial de la Ciudad Autónoma de Melilla (BOME) (2019). Acuerdo del consejo de gobierno de fecha 13 de mayo de 2019 relativo a la aprobación de las instrucciones para la gestión del padrón municipal de habitantes de Melilla. BOME 5656, 1903. Recuperado de https://bomemelilla.es

Borruso, G. (2003). Network density and the delimitation of urban areas. Transactions in GIS, 7(2), 177-191. https://doi.org/10.1111/1467-9671.00139

Centre for Advanced Spatial Analysis (2018). The Bartlett Centre for Advanced Spatial Analysis. Recuperado de https://www.ucl.ac.uk/bartlett/casa

Chou, T. L., \& Lin, Y. C. (2007). Industrial Park Development across the Taiwan Strait. Urban Studies, 44(8), 1405-1425. https://doi.org/10.1080/00420980701373529

Ciudad Autónoma de Melilla (2015). Plan de Movilidad Sostenible. Recuperado de https:// medioambientemelilla.es/las-escalas-de-melilla-y-sus-relaciones-con-la-movilidad/

Comisión Europea (1985). Documentos relativos a la adhesión del Reino de España y de la República Portuguesa a las Comunidades Europeas. Diario Oficial Comunidad Europea. L 302, 15 de noviembre de 1985. Recuperado de https://eur-lex.europa.eu/legal-content/ES/TXT/?uri=OJ:L:1985:302:TOC

Comisión Europea (2004). Reglamento (CE) no 1140/2004 del Consejo, de 21 de junio de 2004, por el que se suspenden los derechos autónomos del arancel aduanero común aplicables a determinados productos pesqueros originarios de Ceuta y Melilla. Diario Oficial Comunidad Europea (DOCE). L 222, 23 de junio de 2004. Recuperado de https://eur-lex.europa.eu/legal-content/ES/ TXT/?uri=OJ:L:2004:222:TOC

Declaración de Barcelona (27-28 de noviembre de 1995). Adoptada en la Conferencia Euromediterránea. Recuperado de http://www.ces.es/TRESMED/docum/dec_Barcelona_1995_es.pdf

Daoudi, F. (2015). Vécu frontalier algéro-marocain depuis 1994: quotidien d’une population séparée. Francia: Editions L'Harmattan.

Delegación del Gobierno en Melilla (2016). Los extranjeros afiliados a la Seguridad Social en Melilla se sitúan en 4.324 en febrero. Notas de Prensa. http://www.seat.mpr.gob.es/portal/delegaciones_gobierno/ delegaciones/melilla/actualidad/notas_de_prensa/notas/2016/03/16_03_17_afilia.html

Dilla, H. (2008). Las ciudades en la frontera: Introducción a un debate. En H. Dilla (Coord), Ciudades en las fronteras. Aproximaciones críticas a los complejos urbanos transfronterizos (pp. 17-29). Recuperado de https://www.academia.edu/8217411/Ciudades_en_la_frontera 
Dilla, H. (2015). Los complejos urbanos transfronterizos en América Latina. Estudios Fronterizos, 16-31, 15-38. https://doi.org/10.21670/ref.2015.31.a01

Dilla, H. \& Breton, I. (2018). Las regiones transfronterizas en América Latina. Revista Latinoamericana, 51, 15-37. Recuperado de https://scielo.conicyt.cl/scielo.php?script=sci_ arttext\&pid=S0718-65682018000300015

Direction de la Comptabilité Nationale (2017). Annuaire Statistique du Maroc, année 2017. Recuperado de https://www.hcp.ma/downloads/Annuaire-statistique-du-Maroc_tl1888.html

Direction Regionale D’Oudja (2012). La región de l'Oriental. Disparités intra-régionales et développement contrasté. Royaume du Maroc. Haut Commissariat au Plan Direction Regionale d'Oujda. Recuperado de http://www.hcp.ma/region-oriental/docs/ETUDESREGIONALES/disparites_intra_regionales.pdf

Duarte, C. M. \& Troncoso, J. C. (2012). La densidad-tiempo: otra perspectiva de análisis de la estructura metropolitana. Scripta Nova, 16. Recuperado de http://revistes.ub.edu/index.php/ScriptaNova/article/ view/14762

Ehlers, G.A.N., Buursink, J., Velde, M. \& Houtum, H.V. (2000). Binational cities: People, institutions and structures. In M.van der Velde \& H. van Houtum (Eds.), Borders, Regions and People (pp. 182-201). Recuperado de https://henkvanhoutum.nl/wp-content/uploads/2013/05/borderingspace.pdf

Euro press (2014). Porteadoras marroquies, heroínas y víctimas de la frontera. Recuperado de https://www. euroxpress.es/noticias/porteadoras-marroquies-heroinas-y-victimas-de-la-frontera

European Commission (2016). Global Human Settlement. Recuperado de https://ghsl.jrc.ec.europa.eu/ datasets.php

European Union (2013). European Observation Network for Territorial Development and Cohesion (ESPON). Recuperado de https://www.espon.eu/programme/espon/espon-2013/espon-2013-programme

European Union (2016). European Observation Network for Territorial Development and Cohesion (SPON). Recuperado de https://www.espon.eu/programme/projects/espon-2020/applied-research-projects

European Union (2016). Network On Urban Research In The European Union (NUREC). Atlas of Agglomerations in the European Union. Recuperado de https://ec.europa.eu/eurostat/ documents/3217494/7596823/KS-01-16-691-EN-N.pdf

Feliu, J., Berzi, M., Martín-Uceda, J., Saberi, R. P. \& i Vivas, M. C. (2018). Cuatro fronteras europeas bajo la lupa. Una metodología para el análisis de los proyectos de cooperación transfronteriza (INTERREG). Documents d'anàlisi geogràfica, 64(3), 443-465. https://doi.org/10.5565/rev/dag.532

Feria, J. (2010). La delimitación y organización espacial de las áreas metropolitanas españolas: una perspectiva desde la movilidad residencia-trabajo. Ciudad y territorio, Estudios territoriales, 164, 189-210.

Feria, J. (2013). Towards a taxonomy of spanish metropolitan areas. Boletín de la Asociación de Geógrafos Españoles, (63), 349-378. Recuperado de https://www.age-geografia.es/ojs/index.php/bage/article/ view/1635/0

Ferrer, X. (2008). Acrobacias fronterizas en Ceuta y Melilla. Explorando la gestión de los perímetros terrestres de la Unión Europea en el continente africano. Documents d'anàlisi geogràfica, (51), 129-149. Recuperado de https://core.ac.uk/download/pdf/39021146.pdf

Ferrer, X. \& Gabrielli, L. (Eds.). (2018). Estados de excepción en la excepción del estado: Ceuta y Melilla. Barcelona: Icaria.

Giband, D. \& Rufi, J. V. (2018). Los espacios transfronterizos europeos: ¿un objeto geográfico de difícil definición? Una aproximación desde la perspectiva de los «soft spaces». Documents d'anàlisi geogràfica, 64(3), 421-441. https://doi.org/10.5565/rev/dag.520

Glassner, M. I. \& De Blij, H. J. (1980). Systematic political geography. New York: John Wiley \& Sons.

González-Páramo, A., González del Rosal, C., Lejarza, A., Rodríguez, V. y Fanjul, G. (2019). Melilla y la excepcionalidad fronteriza. Recuperado de https://porcausa.org/

González, C. \& Pérez, A. (2008). Ceuta y Melilla: nuevos elementos en el escenario. Boletín Elcano, (109), 7. Recuperado de http://www.realinstitutoelcano.org/wps/portal/rielcano_ es/contenido/! ut/p/a1/04_Sj9CPykssy0xPLMnMz0vMAfGjzOKNQ1zcA73dDQ38. YKNDRwtfN1cnf2cDf1DjfULsh0VAepxmvs!/?WCM_GLOBAL_CONTEXT=/elcano/Elcano_es/ Zonas_es/ARI159-2008 
Goye, M. D. C. B. (2011). La situación laboral del trabajador transfronterizo en la ciudad autónoma de Melilla. In F.J. García Castaño y N. Kressova (Coords), Actas del I Congreso Internacional sobre Migraciones en Andalucía (pp. 327-335). Recuperado de https://dialnet.unirioja.es/servlet/ articulo? codigo $=4031843$

Hall, P. G. \& Pain, K. (Eds.). (2006). The polycentric metropolis: learning from mega-city regions in Europe. Recuperado de http://www.strategvest.ro/media/dms/file/Resurse/The\%20Polycentric\%20 Metropolis\%202006.pdf

Haut-Commissariat au Plan du Maroc-Centre National de Documentation (2014). Recensement Général de la Population et de l'Habitat, 2014. Base de données statistiques. Recuperado de https://www.hcp. $\underline{\mathrm{ma} / g l o s s a r y / R e c e n s e m e n t-G e n e r a l-d e-l a-P o p u l a t i o n-e t-d e-l-H a b i t a t}$ gw115.html

Haut-Commissariat au Plan du Maroc-Centre National de Documentation (2016). Commerce exterior 2016. Population 2016. Base de données statistiques. Recuperado de https://www.hcp.ma/Centrenational-de-documentation_a723.html

Haut-Commissariat au Plan du Maroc-Centre National de Documentation (2016). Enquête Nationale sur l'Emploi, 2016. Base de données statistiques. Recuperado de https://www.hcp.ma/Emploi_r67.html

Herzog, L. A. (1990). Where North Meets South: Cities, Space, and Politics on the United States-Mexico Border. Texas: University of Texas Press.

Herzog, L. A. \& Sohn, C. (2014). The cross-border metropolis in a global age: A conceptual model and empirical evidence from the US-Mexico and European border regions. Global Society, 28(4), 441-461. https://doi.org/10.1080/13600826.2014.948539

Iglesias, M. (2011). La cooperación transfronteriza Andalucía-Norte de Marruecos. Balance y perspectivas. Recuperado de https://www.centrodeestudiosandaluces.es/datos/publicaciones/ CooperacionTransfronteriza.pdf

Instituto Nacional de Estadística (INE) (2014). Contabilidad Regional de España, 2014. Recuperado de https://www.ine.es/dyngs/INEbase/es/operacion. $\underline{\mathrm{htm} ? \mathrm{c}=\text { Estadistica C\&cid=1254736167628\&menu=resultados\&idp }=1254735576581}$

Instituto Nacional de Estadística (INE) (2018). Contabilidad Regional de España, 2018. Recuperado de https://www.ine.es/dyngs/INEbase/es/operacion.

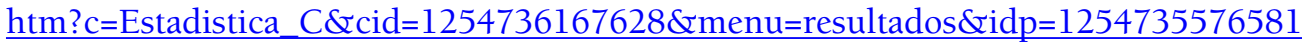

Instituto Nacional de Estadística (INE) (2016). Encuesta de población activa, 2016. Recuperado de https://www.ine.es/dyngs/INEbase/es/operacion.

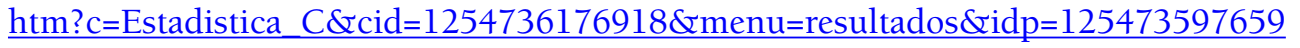

Instituto Nacional de Estadística (INE) (2019). Encuesta de población activa, 2019. Recuperado de https://www.ine.es/dyngs/INEbase/es/operacion.

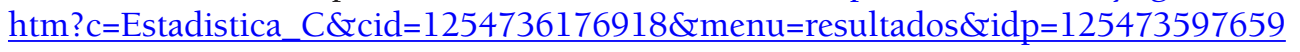

Instituto Nacional de Gestión Sanitaria (INGESA) (2018). Memoria 2017. Recuperado de http://www. ingesa.mscbs.gob.es/estadEstudios/documPublica/internet/pdf/Memoria_2017.pdf

Jessop, B. \& Sum, N.L. (2000). An entrepreneurial city in action: Hong Kong's emerging strategies in and for (inter-)urban competition". Urban Studies, 37(12), 2287-2313. Recuperado de https://doi. org/10.1080/00420980020002814

Jessop, B. (2004). La economía política de la escala y la construcción de las regiones transfronterizas. EURE (Santiago), 30(89), 25-41. http://dx.doi.org/10.4067/S0250-71612004008900002

Kardal, B. (2012). Le chômage dans la region de l'Oriental: pourquoi est-il toujours si conteste et si critique?. Recuperado de http://www.hcp.ma/region-oriental/docs/emploi2011/emploikb.pdf

Kearney, M. (2008). La doble misión de las fronteras como clasificadoras y como filtros de valor. En L. Velasco Ortiz (Coord.), Migración, fronteras e identidades étnicas transnacionales (pp. 79-116). México: El Colegio de la Frontera Norte.

López, A. M. (2012a). The political desing of migration control in Southerm Europe. In C. Cortázar, M-C. Parra, B. Segaert \& C. Timmerman (Eds.), European Migration and Asylum Policies: Coherence or Contradiction? (pp. 205-214). Bruselas: Bruylant. 
López, A. M. (2012b). Donde el sur confluye con el norte: Movimientos migratorios, dinámica económica y seguridad en las relaciones bilaterales entre España y Marruecos. Recuperado de http://www.proyectos. cchs.csic.es/circular/sites/default/files/documents/lopez-sala_2012.pdf

López Suárez, E. (2007). Assessment of transport infrastructure plans: A strategic approach integrating efficiency, cohesion and environmental aspects (Tesis Doctoral). Recuperado de http://oa.upm.es/373/

Martín, J.A. (2015). La problemática de los trabajadores transfronterizos. Ceuta: Fundación Sindical de Estudios.

Martín-Uceda, J. \& Vivas, M. C. (2018). Actores y proyectos transfronterizos en las fronteras ibéricas: análisis comparativo a partir de INTERREG IV-A. BAGE, (78), 154-179. http://dx.doi.org/10.21138/ bage. 2432

Mendoza, J. E. (2010). El mercado laboral en la frontera norte de México: estructura y políticas de empleo. Estudios fronterizos, 11(21), 9-42. Recuperado de http://www.scielo.org.mx/pdf/estfro/ v1ln2l/v1ln2lal.pdf

Migreurop (2016). Ceuta y Melilla, centros de selección a cielo abierto a las puertas de África. Informe 2015. Migreurop. Federación SOS Racismo.

Ministère de l'Equipement, du Transport, de la Logistique et de l'Eau (METLE) (2016). Recueil du Trafic Routier 2016. Trafic Routier. METLE. Recuperado de http://www.equipement.gov.ma/InfrastructuresRoutieres/Reseau-Routier-du-Royaume/Pages/Trafic-Routier.aspx

Ministerio de Fomento (2017). Atlas Estadístico de las Áreas Urbanas Españolas. Recuperado de https:// www.fomento.gob.es/portal-del-suelo-y-politicas-urbanas/atlas-estadistico-de-las-areas-urbanas

Ministerio de Fomento (2018). CORINE Land Cover 2018 (España). Centro Nacional de Información Geográfica. Recuperado de https://datos.gob.es/es/catalogo/e00125901-spaignclc2018

Organización para la Cooperación y el Desarrollo Económicos (OECD) (2013). Regions and Innovation. Collaborating across Borders. https://dx.doi.org/10.1787/9789264205307-en

Peña, S. (2008). Ciudades y fronteras: Los retos de la planificación transfronteriza. En H. Dilla (Coord.) Ciudades en la frontera (pp. 263-283). Recuperado de https://www.academia.edu/8217411/Ciudades en_la_frontera

Planet, A. I. (2002). La frontière comme ressource: le cas de Ceuta et Melilla. In C. Jocelyne (Dir.), La Méditerranée des réseaux. Marchands, entrepreneurs et migrants entre l Europe et le Maghreb. Maisonneuve et Larose-MMSH.

Procesa (2011). Guía fiscal para invertir en Ceuta. Revisión 2011. Recuperado de https://www.procesa.es/ index.php?option=com content $\&$ view $=$ article $\&$ id $=88 \&$ Itemid $=102$

Rodríguez, V. \& Fanjul, G. (2017). La industria del control migratorio. ¿Quién gana en España con las politicas fronterizas de la Unión Europea. Recuperado de https://www.porcausa.org/industriacontrolmigratorio/ media/porcausa_LaIndustriaDelControlMigratorio.pdf

Rosière, S. (2011). Teichopolitics: the Politics of Border Closure. Si Somos Americanos. Revista de Estudios Transfronterizos, XI(1), 151-163. Recuperado de https://www.researchgate.net/publication/267959341_ TEICHOPOLITICS_THE_POLITICS_OF_BORDER_CLOSURE_Teichopolitica_la_politica_de cierre_de_la_frontera

Rouyame du Maroc (2014). Recensement Général de la Population et de l'Habitat 2014. Recuperado de https://rgph2014.hcp.ma/downloads/Publications-RGPH-2014_t18649.html

Salom, J. \& Albertos, J. M. (2014). Delimitación y caracterización de los nuevos espacios urbanos valencianos. Boletín de la Asociación de Geógrafos Españoles, (64), 127-149. Recuperado de https:// www.age-geografia.es/ojs/index.php/bage/article/view/1692

Sohn, C. (2014). Modelling cross-border integration: The role of borders as a resource. Geopolitics, 19(3), 587-608. https://doi.org/10.1080/14650045.2014.913029

Sultán, M. (2002). Activités urbaines danas la ville de Nador: entre l'extension spatiale y l'urbanisme. In Groupe de recherches Géographiques sur le Rif (Ed.), Urbanisation et urbanisme dans les montagnes rifaines (Maroc) (pp. 95-122). Tétouan (Marroc): Groupe de recherches Gépgraphiques sur le Rif. 
Troin, J.F. (2002). L'urbanisation dans le Rif: quelques tendances récentes. In Groupe de recherches Géographiques sur le Rif (Ed.), Urbanisation et urbanisme dans les montagnes rifaines (Maroc) (pp. 39-51). Tétouane (Marroc): Groupe de recherches Gépgraphiques sur le Rif.

United Nations Development Programme (2015). Human Development Report 2015. Recuperado de http:// hdr.undp.org/sites/default/files/2015_human_development_report.pdf

Valero, M. (2008). Ciudades transfronterizas e interdependencia comercial en la frontera Venezuela/ Colombia. Ciudades en la frontera, 67-96. Recuperado de https://www.academia.edu/8217411/ Ciudades en la frontera

Wong-González, P., Oddone, N. y Barajas, M.R. (2017). Fronteras y procesos de integración regional. Estudios comparados entre América y Europa. México: El Colef. 